Bundesgesundheitsbl 2018 · 61:448-473 https://doi.org/10.1007/s00103-018-2706-2 (c) Springer-Verlag GmbH Deutschland, ein Teil von Springer Nature 2018

\section{Prävention postoperativer Wundinfektionen}

\section{Empfehlung der Kommission für Krankenhaushygiene und Infektionsprävention (KRINKO) beim Robert Koch-Institut}

beit mit dem Krankenhaushygieniker entsprechend den örtlichen Gegebenheiten und nach Risikoanalyse in detaillierte Ausführungspläne und Arbeitsanweisungen umgesetzt werden. Diese Festlegungen sollten durch eine Einweisung neuer Mitarbeiter und regelmäßige Schulung aller Mitarbeiter, sowie durch technische Überprüfungsmaßnahmen ergänzt werden.

\subsection{Geltungsbereich und Begründung der Überarbeitung}

Die vorliegenden Empfehlungen befassen sich mit der Prävention und Kontrolle von nosokomialen Infektionen im Operationsgebiet und sich davon ausbreitenden Infektionen, im englischsprachigen Schrifttum als Surgical Site Infections (SSI) bezeichnet. Nicht eingeschlossen sind die Behandlung von bestehenden Wundinfektionen und Präventionsmaßnahmen in Zusammenhang mit peripheren oder zentralen Gefäßzugängen.

Spezielle Konstellationen (zum Beispiel die Vermeidung von Infektionen in Zusammenhang mit präexistent kontaminierten Wunden einschließlich Verbrennungswunden) erfordern zusätzliche, über die nachfolgenden Hinweise hinausgehende Präventionsmaßnahmen.

Die Empfehlung löst folgende Empfehlungen $\mathrm{ab}$ und fasst diese zusammen:

- Anforderungen der Hygiene bei Operationen und anderen invasiven Eingriffen (2000)

\footnotetext{
${ }^{1}$ Wenn jeweils nur entweder die männliche oder die weibliche Form verwendet wird, ist das der sprachlichen Übersichtlichkeit geschuldet und stellt keine Diskriminierung des jeweils anderen Geschlechts dar.
}

rinnen und Mitarbeitern vor nosokomialen bzw. berufsbedingten Infektionen. $\mathrm{Zu}$ einem wirksamen Infektionsschutz tragen persönliche Verhaltensweisen, patientenbezogene spezifische Schutzmaßnahmen, betrieblich-organisatorische, bauliche und apparativ-technische Präventionsmaßnahmen bei. Deren wechselseitige Gewichtung wird wesentlich durch die medizinische Aufgabenstellung einer Operationsabteilung und die jeweiligen örtlichen Bedingungen und Abläufe bestimmt. Die vorliegende Empfehlung muss deshalb in Zusammenar-
- Prävention postoperativer Infektionen im Operationsgebiet (2007) 


\begin{tabular}{|c|c|}
\hline \multicolumn{2}{|c|}{ Abkürzungen } \\
\hline ASA-Score & $\begin{array}{l}\text { American Society of Anesthesio- } \\
\text { logists Score }\end{array}$ \\
\hline$A O R N$ & $\begin{array}{l}\text { Association of periOperative } \\
\text { Registered Nurses }\end{array}$ \\
\hline BfArM & $\begin{array}{l}\text { Bundesinstitut für Arzneimittel } \\
\text { und Medizinprodukte }\end{array}$ \\
\hline$B M I$ & Body mass index \\
\hline CoNS & $\begin{array}{l}\text { Koagulase-negative Staphylo- } \\
\text { kokken }\end{array}$ \\
\hline$D R G$ & Diagnosis Related Groups \\
\hline$E B M$ & $\begin{array}{l}\text { Einheitlicher Bewertungsmaß- } \\
\text { stab }\end{array}$ \\
\hline$E C D C$ & $\begin{array}{l}\text { European Centre for Disease } \\
\text { Prevention and Control }\end{array}$ \\
\hline IfSG & Infektionsschutzgesetz \\
\hline HTA-Bericht & $\begin{array}{l}\text { Health Technology Assessment- } \\
\text { Bericht }\end{array}$ \\
\hline$H I V$ & Humanes Immundefizienz-Virus \\
\hline KRINKO & $\begin{array}{l}\text { Kommission für Krankenhaushy- } \\
\text { giene und Infektionsprävention }\end{array}$ \\
\hline$L A F$ & Laminar Air flow \\
\hline $\min$ & Minute \\
\hline MPBetreibV & $\begin{array}{l}\text { Medizinprodukte-Betreiberver- } \\
\text { ordnung }\end{array}$ \\
\hline MPG & Medizinproduktegesetz \\
\hline MRE & multiresistente Erreger \\
\hline MRSA & $\begin{array}{l}\text { Methicillin resistenter } \\
\text { Staphylococcus aureus }\end{array}$ \\
\hline NICE & $\begin{array}{l}\text { National Institute for Health and } \\
\text { Care Excellence }\end{array}$ \\
\hline$O P$ & Operation \\
\hline$P A P$ & $\begin{array}{l}\text { Perioperative parenterale } \\
\text { Antibiotikaprophylaxe }\end{array}$ \\
\hline RKI & Robert Koch-Institut \\
\hline RLTA & Raumlufttechnische Anlagen \\
\hline$S G B V$ & $\begin{array}{l}\text { Sozialgesetzbuch (SGB) Fünftes } \\
\text { Buch (V) }\end{array}$ \\
\hline $\begin{array}{l}\text { SSI } \\
\text { TAV }\end{array}$ & $\begin{array}{l}\text { Surgical Site Infections } \\
\text { turbulenzarme Verdrängungs- } \\
\text { strömung }\end{array}$ \\
\hline TRBA & $\begin{array}{l}\text { Technische Regeln für } \\
\text { Biologische Arbeitsstoffe }\end{array}$ \\
\hline WHO & World Health Organization \\
\hline
\end{tabular}

- Anforderungen der Hygiene beim ambulanten Operieren in Krankenhaus und Praxis (1997)

- Kommentar der KRINKO zur DIN 1946-4 (2008) (Epidem. Bulletin 4/2010)

Die jeweils aktuellen evidenzbasierten Empfehlungen der Kommission für Kran- kenhaushygiene und Infektionsprävention sind auf den Internetseiten des RKI unter http://www.rki.de/DE/Content/Infekt/Krankenhaushygiene/Kommission/ kommission_node.html aufgeführt.

Die Neuauflage und Zusammenfassung waren notwendig, weil (i) seit der Erstauflage der „Anforderungen der Hygiene bei Operationen und anderen invasiven Eingriffen" mehr als 15 Jahre vergangen sind, so dass eine Aktualisierung der Empfehlung notwendig wurde. (ii) Zudem lassen sich mit der Weiterentwicklung der invasiven Behandlungen diese immer weniger trennscharf von Operationen im klassischen Sinne unterscheiden. (iii) Schließlich entbehrt die Sonderbehandlung ambulanter Operationen nur wegen des Attributs „ambulant" der Grundlage unter dem Aspekt der Infektionsprävention. (iv) Zudem sollten die verschiedenen Ausgangspapiere in eine einheitliche Empfehlung zusammengefügt werden. Die Empfehlung gilt für alle Operationen im Sinne der $\bullet$ Tab. 1.

\subsection{Bezug zu anderen KRINKO- Empfehlungen}

An den Geltungsbereich dieser Empfehlung grenzen folgende weitere Empfehlungen der Kommission für Krankenhaushygiene und Infektionsprävention an, welche sinngemäß und ergänzend Gültigkeit haben, ohne dass dies jeweils einer einzelnen Erwähnung bedarf:

- Empfehlungen zur Händehygiene,

- Anforderungen an die Hygiene bei der Reinigung und Desinfektion von Flächen,

- Anforderungen an die Hygiene bei der Aufbereitung von Medizinprodukten,

- Personelle und organisatorische Voraussetzungen zur Prävention nosokomialer Infektionen,

- Empfehlung zum Kapazitätsumfang für die Betreuung von Krankenhäusern und anderen medizinischen Einrichtungen durch Krankenhaushygieniker/innen,

- Infektionsprävention im Rahmen der Pflege und Behandlung von Patienten mit übertragbaren Krankheiten,
- Empfehlungen zur Prävention und Kontrolle von Methicillin-resistenten Staphylococcus aureus-Stämmen (MRSA) in medizinischen und pflegerischen Einrichtungen,

- Hygienemaßnahmen bei Infektionen oder Besiedlung mit multiresistenten gramnegativen Stäbchen,

- Ergänzung zu den „Hygienemaßnahmen bei Infektionen oder Besiedlung mit multiresistenten gramnegativen Stäbchen" (2012) im Rahmen der Anpassung an die epidemiologische $\mathrm{Si}$ tuation,

- Mitteilung der Kommission für Krankenhaushygiene und Infektionsprävention zur Surveillance (Erfassung und Bewertung) von nosokomialen Infektionen (Umsetzung von $\$ 23$ IfSG),

- Surveillance von postoperativen Wundinfektionen in Einrichtungen für das ambulante Operieren gemäß $\$ 23$ Abs. 1 IfSG; mit Erläuterungen,

- Anforderungen an die Hygiene bei Punktionen und Injektionen,

- Prävention und Kontrolle Katheterassoziierter Harnwegsinfektionen,

- Prävention Gefäßkatheter-assoziierter Infektionen,

- Bekanntmachung des Robert KochInstitutes zu Surveillance nosokomialer Infektionen sowie die Erfassung von Krankheitserregern mit speziellen Resistenzen und Multiresistenzen,

- Erläuterungen zu den Empfehlungen der Kommission für Krankenhaushygiene und Infektionsprävention zur Surveillance von postoperativen Wundinfektionen in Einrichtungen für das ambulante Operieren,

- Vollzugshilfe zur Entsorgung von Abfällen aus Einrichtungen des Gesundheitsdienstes der Bund/Länder-Arbeitsgemeinschaft Abfall.

\subsection{Kategorien für die Empfehlungen der KRINKO}

Ihre Empfehlungen (siehe Kap. 4) klassifiziert die KRINKO entsprechend ihren Festlegungen aus dem Jahre 2010 [1] wie folgt: 
Kategorie IA: Diese Empfehlung basiert auf gut konzipierten systematischen Reviews oder einzelnen hochwertigen randomisierten kontrollierten Studien.

Kategorie IB: Diese Empfehlung basiert auf klinischen oder hochwertigen epidemiologischen Studien und strengen, plausiblen und nachvollziehbaren theoretischen Ableitungen.

Kategorie II: Diese Empfehlung basiert auf hinweisenden Studien/Untersuchungen und strengen, plausiblen und nachvollziehbaren theoretischen Ableitungen.

Kategorie III: Maßnahmen, über deren Wirksamkeit nur unzureichende oder widersprüchliche Hinweise vorliegen, deshalb ist eine Empfehlung nicht möglich.

Kategorie IV: Anforderungen, Maßnahmen und Verfahrensweisen, die durch allgemein geltende Rechtsvorschriften zu beachten sind.

\subsection{Begriffsbestimmungen}

Unter hygienisch-infektiologischen Aspekten werden im vorliegenden Text die in - Tab. 1 angegebenen Begriffe unter den dortigen Definitionen verwendet.

\section{Epidemiologie und Pathophysiologie postoperativer Infektionen im Operationsbereich (SSI)}

\subsection{Inzidenz/Prävalenz}

In deutschen Krankenhäusern wurden im Jahre 2012 knapp 18 Millionen stationäre Behandlungen durchgeführt, dabei rund 51 Millionen Operationen und medizinische Prozeduren [2]. SSI sind mit einem Anteil von ca. $24 \%$ die häufigsten nosokomialen Infektionen in deutschen Akutkrankenhäusern [3]. Für das Jahr 2006 ging man in deutschen Krankenhäusern von ca. 255.000 SSI aus [4]. Dabei gibt es eine große Variabilität der SSI-Raten in Abhängigkeit von der OP-Art. Anhaltszahlen nach OP-Arten finden sich auf der Website des Nationalen Referenzzentrums für die Surveillance von nosokomialen Infektionen ${ }^{2}$.

Die Identifikation einer SSI in Hinblick auf therapeutische Konsequenzen ist eine

${ }^{2}$ http://www.nrz-hygiene.de diagnostische ärztliche Aufgabe. Für Surveillancezwecke kann sie auf der Basis der CDC- [5] bzw. KISS-Definitionen ${ }^{2}$ an geschultes nicht-ärztliches Personal delegiert werden. Die Rate der zu erwartenden SSI variiert nach Art der vorangegangenen Operation, nach der Kontaminationsklasse der Operation (s. unten), nach patientenindividuellen und nach operationsspezifischen Risiken sowie nach anderen Einflussfaktoren.

\subsection{Pathophysiologie der Manifestation von SSI}

Die Wahrscheinlichkeit der Manifestation einer SSI wird im Wesentlichen durch drei Faktorengruppen determiniert: Menge, Art und Pathogenität/Virulenz des (endogen oder exogen eingebrachten) mikrobiellen Inokulums (2.2.1), präexistente infektionsfördernde Umstände beim $\mathrm{Pa}$ tienten (2.2.2) und operationstechnische Bedingungen (2.2.3). Dem Übergang von der Inokulation zur manifesten Wundinfektion liegt eine „Imbalance der ErregerWirt-Beziehung" zu Grunde [6]. Es kann davon ausgegangen werden, dass sich die infektionsfördernden Faktoren wechselseitig beeinflussen und ggf. verstärken [7]. So ist z. B. bei gleichzeitigem Einbringen eines Implantats ein geringeres Inokulum zur Auslösung einer Infektion erforderlich als ohne Implantat. Implantat abhängige Faktoren (Design, Material, Allergenität) können das Infektionsrisiko bei Osteosynthese-Implantaten beeinflussen $[8,9]$.

\subsubsection{Mikrobielles Inokulum}

Erregerreservoire. Erreger von SSI in einer Operationswunde können aus unterschiedlichen Quellen stammen: (a) aus dem Operationsgebiet des Patienten, z. B. bei der Eröffnung des Dickdarms, durch Unfall verschmutzte Operationswunde, etc. (endogener Keimeintrag), (b) aus anderen Körperregionen des Patienten (endogener Keimeintrag), oder (c) aus der belebten oder unbelebten Umgebung des Patienten während der Operation (exogener Keimeintrag).

Zu (a) vorbestehende mikrobielle Besiedlung im Operationsgebiet. In Abhängigkeit vom vorbestehenden Kontami- nationsgrad der betroffenen Körperregion werden Operationen in Gruppen unterteilt [10]:

- in nicht kontaminierter Region (Gr. I),

- in sauber-kontaminierter Region (Gr. II),

- in kontaminierter Region (Gr. III) und

- in manifest infizierter Region (Gr. IV)

Operationen bei Patienten, die mit multiresistenten Erregern [z.B. MRSA, VRE, MRGN] besiedelt sind, sind nur dann der Gruppe IV zuzuordnen, wenn es sich um eine Infektion mit diesen Erregern im OPGebiet handelt [5].

Mit dem Ausmaß der vorbestehenden Kontamination nimmt die Wahrscheinlichkeit einer manifesten SSI zu [11, 12].

\section{Zu (b) mikrobielle Besiedlung aus ande-} ren Körperregionen. Beispiele für außerhalb des OP-Gebiets liegende Erregerreservoire für den endogenen Keimeintrag sind die nasale Kolonisierung mit $S$. aureus, die patienteneigene Darmflora, Infektionen an entfernt liegenden Körperstellen oder an entfernt liegenden Implantaten, bzw. an entfernt liegenden, nicht heilenden Wunden, etc. Der endogene Infektionsweg ist nicht vollständig zu verhindern, weil sich die physiologische Flora von Haut und Schleimhäuten auch bei sorgfältiger präoperativer Antiseptik nicht vollständig eliminieren lässt. Die Bedeutung endogener Keimquellen zeigt sich in der Wirksamkeit vieler präund perioperativer Hygienemaßnahmen (siehe nachstehende Abschnitte).

Zu (c) mikrobielle Besiedlung während der Operation. Der Eintrag von Erregern von außen während der Operation (exogener Eintrag) wird zum Beispiel sichtbar durch die erhöhte SSI-Rate bei perforiertem OP-Handschuh [10], einen identischen Erregernachweis auf der Hand des Chirurgen und bei korrespondierender SSI [13], der Reduktion der SSI-Rate durch Einsatz erregerdichter Textilien für die $\mathrm{Pa}$ tientenabdeckung und OP-Kleidung [14], den Anstieg des SSI-Risikos mit wachsender Anzahl und Personenbewegung im OP [15] oder ein erhöhtes SSI-Risiko bei offenen Drainagen [16]. Der Luft im OP-Raum kommt als Erregerreservoir eine untergeordnete Bedeutung zu (Details siehe 3.3). 
Tab. 1 Begriffsdefinitionen für den vorliegenden Text

Implantat

Dauerhaftes Implantat

Passageres Implantat

Operation (OP)

Offene Operation

Minimalinvasive Operation

Interventionelle Operation

Eingriff

Verfahrenswechsel

Operations-(OP-)

Abteilung

Operationsraum

Eingriffsraum
Diagnostisch oder therapeutisch eingebrachter Fremdkörper nicht menschlichen Ursprungs (Metall, Kunststoff, Keramik oder anderweitig artifizielles Material)

Implantat, welches bestimmungsgemäß dauerhaft im Körper verbleibt (auch wenn es ggf. nach einer gewissen Liegedauer gegen ein Folgeimplantat zu tauschen ist). Beispiele: Endoprothesen, Herzklappen, endovaskuläre Stents

Implantat, welches bestimmungsgemäß nach einer bestimmten Liegedauer entfernt werden soll oder kann. Beispiel: Osteosynthese-Implantat

Diagnostische und/oder therapeutische Maßnahme, die mit Durchtrennung der Haut bzw. Schleimhaut und ggf. tieferer Gewebeschichten einschließlich knöcherner Strukturen einhergeht - unter Ausschluss von Injektionen und Punktionen

Anm.: Der Begriff „Operationen“ wird im Folgenden als gemeinsamer Oberbegriff verwendet

Der Zugang zum Zielorgan erfolgt durch eine so ausgiebige Eröffnung des Körpers, dass die vorgesehenen Manipulationen unter direkter Sicht des Auges möglich sind

Die Sicht auf das Operationsfeld und das Zielorgan erfolgt vornehmlich durch Optiken. Die Exposition (Haut-/Schleimhautdurchtrennung und Präparation tieferer Schichten) erfolgt nur in dem für das Einbringen der Optiken und Instrumente sowie ggf. zur Bergung von Gewebeteilen notwendigen Maße. Gleichgestellt sind Maßnahmen mit minimaler Weichteildurchtrennung und ohne optische Exposition des Zielorgans (z. B. perkutane Fixierung von Knochenbrüchen)

Zielorgan ist z. B. die innere Oberfläche des Herz-Kreislauf-Systems bzw. die Gefäßadventitia. Der Zugang erfolgt auf kleinst möglichem Weg von der Haut zum Gefäßlumen bzw. zur Herzhöhle

Der Begriff „Eingriff“ wird im allgemeinen Sprachgebrauch uneinheitlich verwendet. Er soll häufig (jedoch nicht immer) eine Operation mit geringerem SSI-Risiko bezeichnen (siehe 4.4). Der vorliegende Text verwendet deshalb diesen Begriff nicht.

Geplanter oder nicht geplanter Übergang vom interventionellen bzw. minimalinvasiven auf ein offenes OP-Verfahren

Eine in sich selbständige Organisationseinheit zur Durchführung von Operationen

Raum innerhalb einer OP-Abteilung, in welchem Operationen durchgeführt werden

Der Begriff „Eingriffsraum“ wird im allgemeinen Sprachgebrauch uneinheitlich verwendet. Häufig (jedoch nicht immer) ist damit ein Raum gemeint, in dem Operationen mit geringerem SSI-Risiko durchgeführt werden. Ist der Raum nicht baulich in eine OP-Abteilung integriert, dient er häufig zusätzlich zur OP-Vor- und -Nachbereitung und anderen Zwecken. Der Stellenwert von Eingriffsräumen ohne Einbindung in eine OP-Abteilung wird unter 4.4 ausgeführt.

Fremdkörper organischen Ursprungs (autolog, allogen, xenogen)
Transplantat

Erregerspektrum. Nosokomiale postoperative Wundinfektionen werden meist durch bakterielle Erreger, selten kombiniert mit Pilzen, verursacht. Das Erregerspektrum kann je nach Operationsregion bzw. Art der Operation variieren [5]. Bestimmte fakultativ pathogene Erreger (zum Beispiel koagulase-negative Staphylokokken, CoNS) treten nur in besonderen Konstellationen, zum Beispiel in Verbindung mit Implantaten auf. - Tab. 2 zeigt auf der Basis von 10.601 SSI-Isolaten den Anteil der wichtigsten Erregerarten nach OP-Gruppen [17].

\subsubsection{Patientenseitige präexistente infektionsfördernde Faktoren}

Einige im allgemeinen Gesundheitszustand des Patienten liegende Faktoren erhöhen generell die Wahrscheinlichkeit einer SSI.
Gleichzeitig wird das Infektionsrisiko im Einzelfall vor allem auch durch die Art der durchzuführenden Operation beeinflusst. - Diabetes mellitus: Es gibt Hinweise darauf, dass ein vorbestehender Diabetes mellitus mit einer erhöhten Rate von SSI einhergeht [12, 18-20], bzw. dass eine optimierte präoperative Diabetes-Einstellung die Rate postoperativer SSI senkt [21-25].

- Adipositas: Risikofaktorenanalysen zeigen, dass ein Body mass index (BMI) von über 25 bzw. 30 einen unabhängigen Risikofaktor für die SSI darstellt [12, 18, 20, 26-28].

- Rauchen: Rauchen kann das Risiko von SSI erhöhen [12, 20, 28-30].

- Anämie: Perioperative Anämie ist ein signifikanter Risikofaktor für SSI bzw. postoperative Letalität $[19,31]$.
- Immunsuppression: Der Einfluss einer Immunsuppression beim Patienten auf die SSI-Rate ist nachgewiesen für eine bestehende HIV-Infektion [3234], Nierentransplantation [35, 36], und für Infektionen im Zusammenhang mit kolorektalen oder laryngealen Karzinomen [37-39]. Dabei wurde im Rahmen der HIV-Infektion ein Zusammenhang zwischen der Schwere der HIV-induzierten Immunsuppression (CD4-Zellzahl) und der Rate von SSI beobachtet [32-34]. Beim kolorektalen Karzinom wurde der Operationstechnik die überwiegende Bedeutung für die SSI-Rate beigemessen [37], während bei Tumoren im Halsbereich neben der postoperativen Tracheostomie [39] auch die Chemotherapie als Risikofaktor identifiziert 
Tab. 2 Häufigste Erreger der SSI bei ausgewählten OP-Arten in \% (OP-KISS-Daten 2010-14, [17])

\begin{tabular}{lllll} 
Erregerart & Abdominalchirurgie & Herzchirurgie & Traumatologie/ Orthopädie & Alle Operationen \\
\hline S. aureus & 4 & 25 & 32 & 20 \\
Enterococcus spp. & 29 & 10 & 11 & 18 \\
$\begin{array}{l}\text { E.coli } \\
\text { CoNS }\end{array}$ & 30 & 5 & 5 & 15 \\
(als alleiniger Erreger) & 1 & 21 & 17 & 10 \\
$\begin{array}{l}\text { P. aeruginosa } \\
\text { a }\end{array}$ & 6 & 3 & 3 & 4
\end{tabular}

wurde [38]. Für eine (perioperative) Dexamethason-Behandlung wurde kein signifikant erhöhtes Risiko einer SSI nach Laparotomie gezeigt [29]. Die WHO empfiehlt, eine bestehende immunsuppressive Behandlung vor einer geplanten $\mathrm{OP}$ nicht in der $\mathrm{Ab}$ sicht einer SSI-Vermeidung zu unterbrechen [40].

- Vorbestehende Infektionen beim Patienten in anderen Körperregionen erhöhen das Risiko einer SSI [5, 41]

- Präoperative Ernährung: Eine präoperative Mangelernährung führt zur signifikanten Erhöhung des Risikos einer SSI [12, 19, 42, 43]. Andererseits konnte ein positiver Einfluss einer angereicherten präoperativen Ernährung im Sinne einer „Immunonutrition" nicht durchgehend nachgewiesen werden [44-47]. Zumindest erleichtert eine „Immunonutrition“ die postoperative Erholung des Patienten, erkennbar an einer kürzeren Verweildauer [45]. Vermehrter Alkoholkonsum hat eine infektionsbegünstigende Wirkung [29].

- Postoperative Ernährung: Generell ist aus infektionsprophylaktischer Sicht postoperativ keine Unterbrechung der Nahrungszufuhr erforderlich. Ein frühzeitiger oraler bzw. enteraler Kostaufbau führt gegenüber einer längerfristigen Nüchternheit zur Verminderung des Risikos einer SSI und wirkt sich günstig auf die Krankenhausverweildauer aus [48].

\subsubsection{Operativ-technische Bedingungen der Operation}

Die Wahl des operativen Verfahrens, des operativen Zugangs, der verwendeten Implantate und anderer Materialen usw. ist vorrangig durch den Patienten und unter Berücksichtigung der lokalen Gegeben- heiten zu treffen. Auf die Verfahrenswahl im Einzelfall nehmen neben infektionspräventiven Aspekten zahlreiche andere Faktoren Einfluss [49]. Die entsprechenden Informationen (siehe 3.1) können in die Überlegungen zur Verfahrenswahl eingehen.

\section{Wissenschaftliche Basis verschiedener Maßnahmen zur Vermeidung von SSI}

\subsection{Prä-/Perioperative organisatorische Maßnahmen}

Präoperative Darmentleerung beim Patienten. $\mathrm{Ob}$ vor abdominalchirurgischen Operationen eine Darmentleerung beim Patienten durchgeführt werden soll, ist keine infektiologische, sondern eine chirurgische Entscheidung. Sofern die präoperative Darmreinigung nicht aus OPtechnischen Gründen für erforderlich angesehen wird, gilt sie aus infektiologischen Gründen als entbehrlich, weil dadurch weder die mikrobielle Besiedlung noch die SSI-Rate reduziert wird [50-57]. Wird die Darmentleerung mit oraler Antibiotikagabe kombiniert, werden im Vergleich zum Verzicht auf beide Maßnahmen SSI, Ileus und Anastomosenleckage signifikant reduziert [58].

Präoperative Haarentfernung beim Patienten. Im Ergebnis einer Vielzahl von Studien ist gesichert, dass der Verzicht auf die präoperative Rasur mit einem geringeren SSI-Risiko korreliert [59, 60]. Sofern eine (Teil-)Haarentfernung aus OPtechnischen Gründen notwendig ist, ist Rasieren mit einer höheren SSI-Rate verbunden als das Kürzen mit einer elektrischen Haarschneidemaschine (Clippen). Zwischen Clippen und chemischer Depilation (Enthaarungscremes) besteht kein signifikanter Unterschied in Bezug auf die SSI-Rate. Allerdings können durch die Creme Hautirritation oder allergische Reaktionen ausgelöst werden [61].

Präoperative Körperreinigung des Patienten. Aus allgemeinhygienischen Gründen wird am Abend vor der OP oder am Tag der OP eine Ganzkörperwäsche oder Duschen empfohlen [62]. Zum Wert einer über die übliche Körperhygiene hinausgehenden präoperativen Ganzkörperreinigung (Waschen oder Duschen/ antiseptische Waschung) gibt es zahlreiche Einzelstudien. HTA-Berichte bzw. Cochrane-Analysen [63-65] ergeben generell unabhängig von der Form der Reinigung und der Wahl der Waschlotion übereinstimmend keinen signifikanten Einfluss auf die SSI-Rate.

Präoperative stationäre Verweildauer. Eine verlängerte präoperative Verweildauer kann mit einem erhöhten SSI-Risiko verbunden sein $[28,41,43,66,67]$. Sofern es sich bei der präoperativen Verweildauer nicht um einen Surrogatparameter der patientenseitigen Morbidität handelt, ist der Effekt nur durch eine mit der Liegedauer zunehmende Wahrscheinlichkeit einer Kolonisation des Patienten mit krankenhausspezifischer Flora zu erklären [12].

Relation OP-Zahl/SSI. Es gibt Hinweise darauf, dass mit zunehmendem Umfang der Erfahrung des Operateurs und/oder der Erfahrung des Teams die Rate der SSI abnimmt [68-71].

Bereichskleidung und Bereichsschuhe. Das Tragen von farbiger, d.h. als solcher erkennbarer Bereichskleidung in der OPAbteilung (und analog in anderen abgegrenzten Funktionsbereichen) ist einge- 
führte Praxis [72], wenngleich bezüglich der OP-Bereichskleidung deren infektionspräventiver Effekt nicht in vergleichenden Studien belegt ist. Bereichskleidung soll dazu dienen, die Verschleppung von Bakterienpopulationen in beide Richtungen (in die OP-Abteilung und heraus) zu vermeiden. Die Rationale für den Wechsel der übrigen Berufskleidung gegen Bereichskleidung ist die nachgewiesene Kontamination der Berufskleidung mit fakultativ-pathogenen Erregern einschließlich MRE [73-78]. Analoges ergibt sich für Bereichsschuhe. Auch ihr Nutzen zur Vermeidung einer Erregerverschleppung in beide Richtungen ist plausibel, wenngleich nicht in Studien belegt. Schuhe sollen aus Gründen des Personalschutzes so beschaffen sein, dass sie maschinell aufbereitet werden können.

Mund-Nasen-Schutz (MNS). Die Wertigkeit des MNS für Patienten und Mitarbeiter ist plausibel, seine Wirkung auf die mikrobielle Belastung der Raumluft ist nachgewiesen [41, 79], seine Wirkung auf die Rate von SSI jedoch nicht in vergleichenden Studien belegt. In der Fachliteratur sind Ausbrüche postoperativer Infektionen beschrieben, in denen vor allem S. aureus und A-Streptokokken von kolonisiertem chirurgischem Personal - insbesondere intraoperativ - auf Patienten übertragen wurden [80-89].

Haarschutz. Für den Haarschutz gilt das für den MNS Gesagte sinngemäß und analog. Auch seine Verwendung erscheint für das OP-Team aus Gründen der Plausibilität unverzichtbar; beim übrigen Personal führen etwaige Manipulationen am Haarschutz erwartbar zur Freisetzung von Hautpartikeln (auch bei allopezischen Mitarbeitern) und Kontamination der Hände. Der Haarschutz kann nur wirksam sein, wenn er Kopfhaare und Barthaare vollständig bedeckt [72].

Schutzbrille bzw. Schutzschild: Bei Gefahr des Verspritzens von Körper- oder Spülflüssigkeiten (septische Chirurgie, Gefäß-, Herzchirurgie, transurethrale Behandlungen, Zahnmedizin, Anästhesie, Arbeiten mit oszillierenden oder rotierenden Geräten, etc.) ist das Tragen einer Schutzbrille bzw. eines Gesichtsschildes aus Gründen des Personalschutzes angezeigt, um den Kontakt mit potentiell infektiöser Körperflüssigkeit zu verhindern [72].

Antiseptik des OP-Feldes. Die präoperative Antiseptik des OP-Feldes nimmt eine Schlüsselstellung in der Prävention von SSI ein, weil bei der Durchtrennung des Integuments (Haut, Schleimhäute, Auge) eine Verschleppung der residenten Flora in die Tiefe des OP-Felds verhindert werden soll. Auf Grund der im Vergleich zu talgdrüsenarmen Arealen höheren Siedlungsdichte der Hautflora auf talgdrüsenreichen, feuchten Arealen wie Rücken, Sternum, Stirn, Kopfhaut und Axilla sind die Herstellerangaben zur unterschiedlichen Einwirkungszeit auf talgdrüsenarmer bzw. -reicher Haut einzuhalten.

Mit dem Ziel, die Erreger bei der operativen Durchtrennung des Integuments nicht in die Tiefe zu verschleppen, wird vor der OP-Feldabdeckung die antiseptische Behandlung des OP-Feldes durchgeführt [90].

Für die Hautantiseptik gehören Alkohol basierte Präparate auf Grund ihrer raschen und guten Wirksamkeit zur ersten Wahl [91]. Während für eine Injektion und Punktion keine remanente Wirksamkeit des Hautantiseptikums benötigt wird, ist bei präoperativer Antiseptik eine remanente Wirkung für die Dauer der OP-Feld-Abdeckung bis zum Wundverschluss für langdauernde Operationen zu erwägen. Alkohole haben zwar eine hohe Sofortwirkung, sind aber nicht remanent wirksam. Durch Zusatz eines remanent wirkenden Antiseptikums zur alkoholischen Formulierung ist eine remanente Wirkung erreichbar. Als remanent wirksame antiseptische Zusätze werden derzeit vor allem Chlorhexidin (Chx) und Octenidindihydrochlorid (Oct) eingesetzt. Durch Zusatz von Chx zu Alkohol wird die Wirksamkeit auf die Hautflora signifikant erhöht, wobei sich die Kombination mit Propan-1-ol am wirksamsten erwies [92]. Ob die Chx-basierte Hautantiseptik der mit PVP-Iod überlegen sei, ist strittig $[93,94]$. Unter Berücksichtigung der höheren Effektivität von Alkoholen mit remanentem Wirkstoffzusatz zur Prävention ZVK-assoziierter Blutstrominfektionen [95] erscheint es sinnvoll, Alkohole mit Zusatz eines remanenten Antiseptikums anzuwenden.

Wird der Chlorhexidin-basierte Propan-2-ol mit einem Applikator 30 Sekunden eingerieben, ist die Wirksamkeit höher als bei üblicher Benetzung [96]. Allerdings wird die Wirksamkeit der sog. assistierten Applikation mittels Applikator auch durch mechanisches Einreiben mittels Kornzange und Tupfer für 30 Sekunden erreicht [97]. In jedem Fall ist die präoperative Hautantiseptik zweistufig durchzuführen, beginnend mit mechanisch intensivierter Auftragung von 30 Sekunden und nachfolgender Benetzung mit der Gesamtdauer der Antiseptik mit der vom Hersteller empfohlenen Einwirkungszeit. Die erneute Antiseptik des Wundrands vor Wundverschluss kann eine infektionspräventive Wirkung haben [98]. Gleiches gilt für mit Polihexanid getränkte Wundauflagen auf die Wundnaht $[99,100]$.

Bei der Auswahl von Schleimhautantiseptika sind die Besonderheiten des OPAreals zu beachten. Z. B. kommen bei zu erwartender Exposition des Antiseptikums mit Knorpel im HNO-Bereich anstelle von Octenidin Polihexanid oder PVP-Iod in Betracht [101]. Am Trommelfell ist Octenidin kontraindiziert [102]. Zur präoperativen Augenantiseptik können wahlweise wässrige Lösung auf Basis von PVP-Iod [103] oder Polihexanid [104] eingesetzt werden.

Hautversiegelung. Ein Verfahren zur präoperativen "Versiegelung" der Haut durch einen Cyanoacrylatfilm wurde bezüglich seiner infektionsprotektiven Wirkung in jüngerer Zeit wiederholt untersucht (unter anderem in [105-112]). Ein HTA-Bericht dazu [113] zeigt zwar eine in den Studien reduzierte Infektionsrate, die Studienlage wird jedoch von den Autoren insgesamt als „schwach“ eingeschätzt; die WHO empfiehlt das Verfahren nicht [40].

\section{Abdeckung des Operationsfeldes und anderer Bereiche des Patienten. Die} Notwendigkeit, die das OP-Feld umgebende Haut steril abzudecken, steht grundsätzlich nicht in Frage, wenngleich dies nie vergleichend untersucht wurde. Das Abdeckmaterial soll flüssigkeitsabweisend (low performance bei erwartet geringem Flüssigkeitsanfall) oder flüs- 
sigkeitsundurchlässig (high performance bei erwartet hohem Flüssigkeitsanfall) sein und keine Abriebpartikel produzieren. Die beiden dafür in Frage kommenden Materialgruppen (beschichtete und aufbereitbare Baumwollmaterialien oder Kunststoff-Einwegmaterialien) sind in ihrer infektionsprotektiven Wirkung gleichwertig [14, 72, 114, 115]. Nach präoperativer Antiseptik und Abtrocknung des OP-Felds wird seine Umgebung unter aseptischen Bedingungen steril abgedeckt. Ein erweitertes Nonkontaminations-Management vor Wundverschluss bei kolorektalen Operationen (Gruppe III) (kompletter Wechsel aller Instrumente und der Abdeckung, Neueinkleidung des Teams mit Händedesinfektion) ergab keinen zusätzlichen Vorteil [116, 117].

Sterile Schutzkleidung. Der Mechanismus der Verbreitung von Erregern in die Wunde wurde von Whyte [118] untersucht. Danach sind die Anforderungen an die OP-Kleidung von Operationsdauer, Menge der anfallenden Flüssigkeit und mechanischer Beanspruchung abhängig. Alle Faktoren müssen berücksichtigt werden, wenn das entsprechende Material ausgewählt wird. Die sterile Schutzkleidung soll eine Barrierefunktion gewährleisten [115], deshalb ist der Gebrauch von Baumwollkitteln aus nicht imprägnierten oder laminierten Baumwollmaterialien wegen der mangelnden Barrierefunktion für bakterientragende Partikel und der Freisetzung von Baumwollpartikeln abzulehnen [72]. Sofern kein erhöhter Flüssigkeitsanfall zu erwarten ist, ist flüssigkeitsabweisende OP-Schutzkleidung (low performance) ausreichend. Bei vorhersehbar erhöhtem Flüssigkeitsanfall soll die OP-Kleidung wasserundurchlässig (high performance) sein (Personalschutz) [114, 119-122]. Die OP-Schutzkleidung sollte außerdem ergonomisch, d.h. funktionell und bequem sein, ausreichende Bewegungsfreiheit gewährleisten und den erforderlichen Wärme- und Feuchtigkeitsaustausch ermöglichen. Sie sollte knöchellang, am Hals eng abschließend sein und die Bereichskleidung komplett überdecken. In der Gestaltung von Kragen und Ärmelbündchen darf der Träger nicht behindert werden. Bewegungsfreiheit, Feuchtigkeitsaustausch und physio- logisch einwandfreie Arbeitsbedingungen sind für ein gutes Arbeiten wichtig [72].

Inzisionsfolie. Bei Anwendung von nicht antiseptisch imprägnierter Inzisionsfolie steigt das SSI-Risiko signifikant [123], weswegen diese Anwendung nicht empfohlen wird [62]. Mit Iod imprägnierte Folie ist antimikrobiell wirksam, wobei Iod in tiefere Hautschichten penetriert [124]. Dadurch wird die Wundkontamination verringert [125] und der mit der Verwendung nicht imprägnierter Folie verbundene Anstieg der SSI-Rate wird aufgehoben [126].

Händewaschung. Die Seifenwaschung ist nicht mehr Bestandteil jeder chirurgischen Händedesinfektion, weil dadurch die Wirksamkeit der Alkohole herabgesetzt wird [127] und zudem über wiederholtes Entfetten die Haut geschädigt wird. Beim Betreten des OP-Bereichs sollen Hände und Fingernägel frei von sichtbarem Schmutz sein, da Bakteriensporen durch Alkohole nicht inaktiviert werden. Die Fingernägel sollen kurzgeschnitten mit den Fingerkuppen abschließen. Die Hände werden möglichst $10 \mathrm{~min}$ vor der Händedesinfektion oder früher gewaschen, spätestens jedoch vor dem Anlegen der Bereichskleidung [128]. Die Hände müssen im weiteren Tagesablauf nur bei Verschmutzung und nach dem Toilettengang erneut gewaschen werden.

Chirurgische Händedesinfektion. Die chirurgische Händedesinfektion wird von allen an der OP Beteiligten vor jeder Operation durchgeführt, um die transiente Hautflora zu eliminieren und die residente Flora so weit wie möglich zu reduzieren. Mittel der Wahl sind alkoholbasierte Präparate. Da durch den Zusatz eines remanent wirksamen Antiseptikums zu alkoholischen Händedesinfektionsmitteln kein Einfluss auf die SSI-Rate nachweisbar ist und sich dadurch aber die Verträglichkeit reduzieren kann, ist beim aktuellen Wissensstand der Zusatz derartiger Wirkstoffe entbehrlich [129].

Weiterführende Erläuterungen zur chirurgischen Händedesinfektion werden in der KRINKO-Empfehlung „Händehygiene in Einrichtungen des Gesundheitswesens" gegeben [130].
OP-Handschuhe. Wegen der nur begrenzten Reduktion der residenten Hautflora durch die chirurgische Händedesinfektion ist das Tragen steriler OP-Handschuhe unerlässlich. Bei aseptischen Operationen der Gruppe I (saubere Operationen) war die SSI-Rate nach Handschuhperforation signifikant höher [10]. Im Ergebnis einer prospektiven Kohortenstudie war der Einfluss der Handschuhperforation auf die SSI-Rate signifikant nur bei solchen OPs sichtbar, bei denen keine perioperative Antibiotikaprophylaxe gegeben wurde [131]. OP-Handschuhe schützen darüber hinaus auch den Träger. Bei bekanntem oder wahrscheinlichem Übertragungsrisiko für HIV oder Hepatitisviren (oder andere blutübertragbare Infektionserreger) vom Patienten sollte ein „double gloving-System“ mit Indikator gewählt werden, weil dadurch der innere Handschuh im Vergleich zum einschichtigen Handschuh signifikant seltener perforiert wird [132-134]. Alternativ kommen OP-Handschuhe mit zusätzlicher antimikrobieller Barriere in Betracht [135].

Handschuhe sind erst nach Trocknung des Händedesinfektionsmittels anzulegen, weil anderenfalls das Perforationsrisiko steigen und Hautirritationen begünstigt würden [136]. Regelhaft muss im Laufe der Operation mit Perforationen oder Mikroperforationen gerechnet werden, so dass sich vor allem bei längerdauernden Operationen oder Operationen mit erhöhter Verletzungsgefahr das Tragen doppelter Handschuhe empfiehlt [137143], zumal mit der Dauer der Operation die bakterielle Besiedlung an den Händen der Operateure ansteigt [137]. Ein routinemäßiger Wechsel der Handschuhe nach festgelegter Zeit kann die Rate der Mikroperforationen senken und die Übertragung von Mikroorganismen verhindern [138, 139], der Einfluss auf die SSI-Rate wurde jedoch bisher nicht untersucht. Nach der manuellen Handhabung scharfkantiger Implantate, der Entfernung von Zementbruchstücken (z. B. bei Endoprothesenwechsel) oder von Explantatbestandteilen (Osteosynthese, Endoprothesenwechsel) ist die Wahrscheinlichkeit der Beschädigung von Handschuhen erhöht, auch ohne dass dies durch die Operateure in jedem Falle sofort bemerkt wird [131]. Bei intraoperativer Handschuhbeschädi- 
gung werden zwei neue sterile OP-Handschuhe angelegt $[144,145]$. Hat sich die Perforation zu OP-Ende ereignet, kann es ausreichend sein, einen frischen sterilen Handschuh über den perforierten Handschuh zu ziehen.

Aus Gründen des Arbeitsschutzes sollen OP-Handschuhe hautverträglich, ungepudert und allergenarm sein. Durch unter dem OP-Handschuh angelegte sterile Baumwollhandschuhe kann einem Feuchtigkeitsstau entgegengewirkt und die Hautverträglichkeit verbessert werden [146].

Fingernägel, Schmuck, etc. Das Tragen künstlicher Nägel konnte als Quelle von Ausbrüchen nosokomialer Infektionen identifiziert werden [147-149]. Der Zusammenhang zwischen Schmuck an den Unterarmen beim OP-Team und dem Auftreten von SSI ist nicht hinreichend untersucht. Eine Studie belegt allerdings die erhöhte Perforationshäufigkeit von OP-Handschuhen beim Tragen von Ringen [150]. Im Übrigen behindern Schmuckstücke die sachgerechte Hygiene und sind mit dem Risiko von Verletzungen verbunden [151].

Operationstechnik. Generell gilt eine schonende Operationstechnik bzw. atraumatisches Gewebehandling als wichtige Voraussetzung für eine primäre Wundheilung und somit für die Vermeidung von SSI [152]. In der Orthopädie/Unfallchirurgie hat der Zusammenhang zwischen dem gewählten operativen Verfahren und der Rate nachfolgender SSI einen relevanten Einfluss auf die Wahl der Operationstechnik genommen [153]. Interventionelle [154, 155] bzw. minimalinvasive Verfahren [156-164] können gegenüber den jeweiligen offenen Operationsverfahren einen infektionspräventiven Vorteil haben, dies jedoch nicht durchgehend [165].

\section{Instrumentarium (Medizinprodukte).} Das mit der Wunde bzw. tieferen Gewebsschichten in Kontakt tretende Instrumentarium muss steril sein. Eine hohe technische Qualität des Instrumentariums trägt zur kürzeren OP-Dauer und atraumatischen OP-Technik bei und ist damit mittelbar infektionspräventiv. Wundrandpro- tektoren (Ringfolien) sollen (vor allem bei Operationen der Gruppe III) eine Kontamination des Wundrandes, der Subkutis und angrenzender Schichten mit körpereigener Flora (zum Beispiel Darmflora) verhindern [166-171]. Ihr infektionspräventiver Vorteil ist jedoch nicht durchgehend nachweisbar [172-175]. Die WHO empfiehlt, ihre Verwendung bei Operationen der Kontaminationsklassen 2, 3 und 4 der Abdominalchirurgie zu erwägen [40]. Skalpell und Elektrokauter unterscheiden sich bezüglich der Infektionsgefährdung nicht [176-178]. Obwohl die residente Flora durch die präoperative Hautantiseptik nur unvollständig eliminiert wird, war im Ergebnis einer prospektiven Studie kein signifikanter Unterschied der SSI erkennbar, je nachdem, ob das Skalpell nach der Hautinzision gewechselt wurde oder nicht, wobei insgesamt die Skalpelle nur in geringer Zahl kontaminiert waren [179]. Auch die WHO gibt diesbezüglich keine Empfehlung ab [40]. Trotz dieser Umstände ergab eine Befragung von 300 Orthopäden, dass $65 \%$ von diesen das Skalpell nach Durchtrennung der Haut wechseln [180].

Das steril abgedeckte Instrumentarium ist im OP-Raum erst unmittelbar vor OPBeginn (Schnitt) aufzudecken; andernfalls kann es zur Kontamination durch Kontakt oder durch in die Raumluft freigesetzte Hautschuppen und Mikroflora seitens des Personals (Reinigungs-, OP-Team) kommen. Diese Schlussfolgerung lässt sich aus Untersuchungsergebnissen im Operationsverlauf ableiten. Danach steigt mit wachsender Personenzahl und -aktivität im OP die mikrobielle Belastung der Raumluft sowie die Größe der Schwebepartikel an [181, 182]. Parallel erhöht sich die mikrobielle Sedimentation auf Instrumente und Implantate [183].

Operationsdauer. Die Operationsdauer wird als unabhängige Variable für die Wahrscheinlichkeit einer SSI benannt [25, 30, 157, 184, 185]. Hierzu wiesen Kim et al. [184] eine stufenweise Erhöhung der SSI-Rate parallel zur OP-Dauer nach. Bei Hüftgelenksendoprothesen war die Dauer der OP ein starker Prädiktor für das Auftreten von SSI $[186,187]$ analog bei herzchirurgischen Operationen [188]. Dabei muss offen bleiben, ob die Operations- dauer (auch) ein Surrogatparameter für die operationstechnische Qualität und/ oder die präexistente Schwierigkeit der Operation sowie die präexistente Morbidität des Patienten ist [69].

Implantate. Zusätzlich eingebrachte Fremdmaterialien (Endoprothesen, Schrauben, etc.) begünstigen die Entstehung einer Infektion- dies u. a. in Abhängigkeit von deren Materialeigenschaften: In der orthopädischen Chirurgie ist zum Beispiel bei sauberen Operationen bei Verwendung von Titanimplantaten bzw. bei Implantaten mit minimalem Knochenkontakt eine signifikant höhere Anzahl von Infektionserregern zur Infektauslösung notwendig als bei Implantaten aus konventionellen Legierungen bzw. Vollkontakt (im Tierexperiment quantitativ, klinisch „dem Grunde nach“ nachweisbar); analoges gilt für die Vorzüge intramedullärer gegenüber extramedullären Implantaten [8, 9, 189].

Durch antiseptische Beschichtung von Nahtmaterial (z.B. Triclosan) soll die Biofilmbildung entlang des Fadens vermindert werden [190, 191]. Es könnte deshalb mit seiner Verwendung zur Reduktion des SSI-Risikos kommen. Die diesbezügliche Studienlage ist uneinheitlich [192-201]. Die WHO empfiehlt die Verwendung unabhängig von der Art der Operation [40], das CDC in der Viszeralchirurgie [202].

Drainagen. Drainagen leiten Sekret ab und sollen damit zur Infektionsprophylaxe beitragen. Das wurde grundsätzlich nur für geschlossene Drainagensysteme gezeigt [16, 203]. Auch für diese ist der Vorteil bezüglich der Vermeidung einer SSI in den aktuellen Studien nicht mehr nachweisbar [204-211]. Für die prophylaktische Drainage konnte in der kolorektalen Chirurgie kein präventiver Einfluss auf die Anastomosenleckage und die SSIRate nachgewiesen werden [212]. Bei der subkutanen Penrose-Drainage war ebenfalls kein signifikanter Einfluss auf die Prävalenz einer SSI nachweisbar [213]. Auch bei Hüftgelenksendoprothesen war die Redondrainage ohne Einfluss auf die SSIRate. Bei spinaler Spondylodese stieg pro Tag der Liegedauer der Drainage das SSIRisiko an [214]. Wunddrainagen sollen daher nicht routinemäßig, sondern nur 
bei gezielter Indikation und so kurzzeitig wie möglich eingesetzt werden [16, 214]. Offene Drainagen sind wegen des Infektionsrisikos nicht zu verwenden. Sofern Drainagen indiziert sind, sollen sie über eine separate Inzision ausgeleitet werden.

Wundverschluss. Durch die Naht tieferer Wundschichten mit kleinen Stichen konnte im Vergleich zu „big bites“ eine Senkung der SSI-Rate erzielt werden [215, 216]. Dünneres Fadenmaterial [217] bzw. Einzelknopfnähte [218] erwiesen sich als günstig. In einem Cochrane Review wurde kein Unterschied zwischen Infektionsraten nach Hautverschluss durch Klammernaht im Vergleich zur konventionellen Naht (nach Venenentnahme im Rahmen der Koronarchirurgie) festgestellt (HTA-Bericht, [219]).

Flächendesinfektion. Die Zwischendesinfektion aller patientennahen Flächen sowie von sichtbar kontaminierten Flächen und des begangenen Fußbodenbereichs im OP gelten als eingeführter Standard, wenngleich deren Stellenwert für die Prävention von SSI und die effektivste Form der Intervention mittels Flächendesinfektion unklar sind [220, 221]. Bei Verzicht auf die Zwischendesinfektion der begehbaren Fußbodenflächen zwischen zwei kleinflächigen Operationen war keine vermehrte mikrobielle Raumluftbelastung nachweisbar [222].

Die allgemeine Notwendigkeit der Flächendesinfektion ergibt sich aus der Kontamination der Flächen im OP [223-225]. Nach der Desinfektion von Fußböden war die Erregerlast auf den Flächen 21-fach, auf anderen Flächen 90-fach geringer als wenn nur gereinigt wurde [226]. Auf Flächen, die nicht regelmäßig in die Aufbereitung einbezogen wurden wie Badges, PC-Tastaturen und PC-Maus, war die Kontamination deutlich höher als auf regelmäßig desinfizierten Flächen [227, 228]. Wurde nur gereinigt, unterschied sich die mikrobielle Belastung der Flächen nicht von der Situation vor der Reinigung [229]. Von kontaminierten OP-Flächen können Erreger vor allem über die Hand aber auch luftgetragen oder über sekundär kontaminierte Medizinprodukte zum Patienten gelangen $[221,230]$. Deshalb fordert der britische National Health Service
[231] die Intensität und Frequenz der desinfizierenden Reinigung in OP-Einheiten auf dem höchsten Level. In den USA empfiehlt die Association of periOperative Registered Nurses (AORN) [232] die desinfizierende Reinigung vor und nach jeder OP und bei Erfordernis während der OP sowie am Tagesende.

Für die Flächendesinfektion können Präparate mit einer kurzen Einwirkzeit (z. B. $15 \mathrm{~min}$ ) verwendet werden, um die Zeit zur Wiederbenutzung der OP-Einheit so kurz wie möglich zu halten. Sofern mit einer Kontamination mit Bakteriensporen, z. B. C. difficile, oder mit unbehüllten Viren, z. B. Papillomviren, zu rechnen ist, müssen Flächendesinfektionsmittel mit sporozider bzw. viruzider Wirksamkeit eingesetzt werden. Für Details der Präparatewahl sowie für die Entscheidung, unter welchen Bedingungen vor Wiederbetreten der Flächen die gesamte Einwirkzeit abgewartet werden muss, wird auf die Empfehlung „Anforderungen an die Hygiene bei der Reinigung und Desinfektion von Flächen“ [233] verwiesen.

Aufbereitung von Instrumenten. Es dürfen nur sachgerecht aufbereitete Medizinprodukte zur Anwendung kommen. Benutzte Instrumente werden nach der Vorbereitung in ein geeignetes, sicher schließbares Gefäß für den Transport zum Ort der Aufbereitung verbracht. Bezüglich der gesamten Aufbereitung von Medizinprodukten wird auf die in $\$ 8 \mathrm{Ab}$ satz 2 MPBetreibV genannte gemeinsame Empfehlung der Kommission für Krankenhaushygiene und Infektionsprävention (KRINKO) beim Robert Koch-Institut (RKI) und des Bundesinstitutes für Arzneimittel und Medizinprodukte (BfArM) zu den „Anforderungen an die Hygiene bei der Aufbereitung von Medizinprodukten“verwiesen [234].

\subsection{Prä-/Perioperative medizinische Maßnahmen}

Präoperative Patientenuntersuchung. Da Infektionen an anderer Körperstelle (außerhalb des OP-Gebiets) Quelle einer SSI werden können [5, 235-237], sollen eitrige umschriebene oder generalisierte Hautinfektionen und andere Infektionen, z.B. auch Zahnwurzelinfektionen, vor elektiven Operationen saniert werden. Bereits eine anamnestisch feststellbare erhöhte Empfindlichkeit gegenüber Hautinfektionen konnte als unabhängiger Risikofaktor für SSI identifiziert werden [238].

\section{Präoperative Dekolonisation der $\mathrm{Pa}$ - tienten bei Operationen mit hohem An-} teil von SSI durch S. aureus. Ein hoher Anteil der durch $S$. aureus verursachten SSI ist dadurch bedingt, dass die Patienten selbst nasale Träger dieses Erregers sind. Für orthopädische Operationen ist bekannt, dass mit $S$. aureus-Kolonisierte ein ca. fünfmal höheres Risiko haben, eine SSI zu entwickeln als nicht-Kolonisierte; es konnte gezeigt werden, dass die Rate von S. aureus-SSI signifikant reduziert werden kann, wenn man die Patienten präoperativ auf $S$. aureus screent und anschließend mit Hilfe von Mupirocin (nasal) und Chlorhexidin (Haut) dekolonisiert [239-241]. Auf Grund von Berichten über erfolgreiche Dekolonisation von MRSA mit Octenidin (Nase, Mundhöhle, Haut) [242] kann beim Versagen des Dekolonisationsversuchs mit Mupirocin oder bei nachgewiesener Resistenz gegen Mupirocin die Anwendung von Octenidin-haltigen Antiseptika zur Dekolonisation erwogen werden. Inzwischen wurden auch klinische Studien publiziert, in denen auf ein präoperatives Screening verzichtet wurde und alle Patienten eine präoperative Dekolonisationsbehandlung erhielten [243]. Neben Mupirocin wurde für die Dekolonisation der Nase vereinzelt auch PVP-Nasensalbe verwendet [244, 245] bzw. nur eine Dekolonisation der Haut durchgeführt [246]. Allerdings besteht bei einer generellen Dekolonisation in höherem Maße das Risiko der Entwicklung von Resistenzen gegenüber $\mathrm{Mu}$ pirocin und Chlorhexidin [247-250].

Orthopädische/traumatologische, kardiologische und ggf. andere Kliniken mit hohem Anteil von Operationen, bei denen postoperative $S$. aureus-Infektionen eine wichtige Rolle spielen, sollten deshalb eine Risikoanalyse durchführen und ggf. eine Dekolonisierungsstrategie entwickeln, die den spezifischen Abläufen Rechnung trägt (z. B. prästationäres Screening und gezielte Dekolonisation vs. ambulante oder stationäre generelle Dekolonisation vor bestimmten festzulegenden 
Operationen). Die Rate der SSI und das Erregerspektrum sollen im Rahmen von Surveillance verfolgt und die Entwicklung von Resistenzen gegen das verwendete Dekolonisierungsmittel regelmäßig beobachtet werden. Zu der Frage, ob Patienten mit bestimmten OP-Arten präoperativ auf 3MRGN gescreent werden sollten, um die perioperative Prophylaxe entsprechend anzupassen, können aktuell mangels gesicherter Daten keine Empfehlungen abgegeben werden.

Die WHO empfiehlt hierzu zusammenfassend [40]:

- Herzchirurgische und orthopädische Patienten mit bekannter S. aureus-

Kolonisation sollten perioperativ intranasal $2 \%$ ige Mupirocin-Salbe erhalten, mit oder ohne Kombination mit Chlorhexidin-Körperwaschungen (strong recommendation, moderate quality of evidence).

- Bei Patienten mit bekannter S. aureusKolonisation und anderen OP-Arten kann die Dekolonisation erwogen werden (conditional recommendation, moderate quality of evidence).

Perioperative parenterale Antibiotikaprophylaxe (PAP). Der Einfluss einer perioperativen parenteralen Antibiotikaprophylaxe auf das Risiko von SSI ist umfangreich untersucht worden. Eine umfassende Darstellung ergibt sich aus dem einschlägigen ECDC technical report [251]. Studien aus jüngerer Zeit (Jahr 2000 und jünger) lassen folgende Trends erkennen: Signifikante Einflüsse sind vor allem nachweisbar bei hohen bis sehr hohen Ausgangswerten der Infektionsraten (Ausgangs-Infektionsrate für saubere Operationen 13-36\%)[252-255], bei Risikopatienten [256-258], für orthopädische Eingriffe mit dauerhaftem Implantat [259, 260], bei der Versorgung von Frakturen langer Röhrenknochen (HTA-Bericht, [261]) und für die Mamma-Chirurgie (HTA-Bericht, [262]). Für saubere Operationen mit niedrigen Ausgangs-Infektionsraten waren Vorteile nicht signifikant oder nicht gegeben [259, 263-271]. Das Antibiotikum muss zum Zeitpunkt der Inzision bereits wirksame Spiegel im OPGebiet erreicht haben [272]; bei lang dauernden Operationen kann dieser durch eine einzelne Folgedosierung aufrechter- halten werden [272]. Eine über den Operationstag hinausgehende PAP ist nicht nur nicht nützlich, sie vergrößert zudem das Risiko von Resistenzentwicklungen [273-284]. Vielfach werden die Vorgaben für eine wirkungsvolle systemische Antibiotikaprophylaxe (insbesondere bzgl. Zeitpunkt und Dauer) nicht eingehalten $[285,286]$, deswegen können gesonderte Erinnerungen oder spezielle Schulungen sinnvoll sein $[286,287]$. Eine interdisziplinäre Gruppe sollte jährlich die PAP-Medikamente anhand der lokalen Erreger- und Resistenzdaten festlegen und die Compliance dabei zu erfassen. Operationen ohne Prophylaxe sollten klar definiert werden.

Zusammenfassend gelten generell folgende Indikationen für die PAP als gesichert [288], mit Auswahl der Antibiotika je nach Prozedur und den zu erwartenden Erregern:

- Risiko einer intraoperativen Kontamination mit nachfolgender SSI aufgrund hoher Erregerexposition im Operationsgebiet (meist bei Vorliegen der Wundklassifikationen sauber-kontaminiert, kontaminiert und schmutzig).

- bei sauberen Operationen Vorliegen eines zusätzlichen Risikofaktors wie Notfalloperation, Osteosynthese, Rückenmarkchirurgie, offene Reposition und interne Fixation von Frakturen, Hochrisikooperation, Operation an großen Gelenken, Einbau von Gefäßund Gelenkimplantaten, Herzklappen sowie anderen alloplastischen Materialien und Ersatz bereits vorhandener Implantate wie Endoprothesen, künstliche Herzklappen u.a. - Versorgung offener Frakturen.

- bei sauberen Operationen mit Infektionsgefährdung auf Grund patienteneigener Risiken und als Folge erheblicher Morbidität, z. B. Operationen bei immunsupprimierten Patienten, bei Patienten mit schweren Grunderkrankungen, bei Patienten mit hohem ASA-Score, Vorbestrahlung, Unterkühlung.

Lokale Antibiotikaanwendung. Durch zusätzliche Anwendung von antibiotisch imprägniertem Zement zur PAP konnte die Rate tiefer SSI bei primärer Hüftgelenksendoprothese signifikant ge- senkt werden, weshalb sich diese Form der antibiotischen Prophylaxe insbesondere bei Revisionsoperationen zunehmend durchsetzt [289, 290]. Dabei ist die Bedeutung weiterer möglicher Einflussfaktoren noch unklar (z.B. optimale Auswahl und Konzentration der Antibiotika, Risiko der Resistenzentwicklung und Einfluss auf die mechanischen Eigenschaften des Zements [291]). In der Kolonchirurgie wurde versucht, in Ergänzung zur systemischen PAP oder als alleinige Maßnahme, durch Zusatz von örtlich wirksamen Antibiotika zu der zur präoperativen Darmentleerung verwendeten Spüllösung das Infektionsrisiko zu senken. Das war in der Mehrzahl der Studien erfolgreich[54, 292-297], in manchen jedoch nicht [298-300]. Im Ergebnis von Metanalysen wird die gleichzeitige parenterale und orale PAP in Verbindung mit mechanischer Darmreinigung empfohlen [54, 301, 302].

Antiseptische Spülung vor Wundverschluss. Im Ergebnis einer Metanalyse wurde dadurch eine signifikante Reduktion der SSI-Rate erreicht. In der Subgruppenanalyse war der stärkste Effekt bei kolorektaler Chirurgie nachweisbar. Wegen des Risikos der Resistenzentwicklung sollten derartige Spülungen allerdings auf keinen Fall mit Antibiotika [303], sondern mit Antiseptika durchgeführt werden. Hierfür sollten oberflächenaktive Wirkstoffe vermieden werden [303]. Octenidin-haltige Lösungen sind wegen der Retention im Gewebe für diese Indikation als ungeeignet anzusehen bzw. bei fehlender Abflussmöglichkeit kontraindiziert [304-306].

Hyperoxygenierung. In jüngerer Zeit wurden in größerem Umfang Studien zu der Frage vorgelegt, ob eine perioperative Hyperoxygenierung des Patienten infektionsprotektiv sei. Die Ergebnisse sind uneinheitlich; positive und negative Resultate halten sich aktuell die Waage [307-316]. Zwei der Studien sind als randomisierte Multicenterstudien bei elektiver Viszeralchirurgie angelegt $[312,314]$. Auch hier ergibt sich ein uneinheitliches Bild, wobei eine Studie mit hohen Ausgangwerten für SSI (Kolonchirurgie, SSI 24,3\%) einen positiven Effekt der Hyperoxygenierung ver- 
zeichnete [314]. Die WHO empfiehlt bei Erwachsenen mit einer Intubationsnarkose eine Hyperoxygenierung von $80 \%$ während der Operation und (wenn möglich) für die ersten 2-6 Stunden postoperativ [40].

Bluttransfusionen. Großer Blutverlust sowie die sich mittelbar hieraus ergebende Notwendigkeit für Bluttransfusionen (letzteres über die immunsuppressive Wirkung von Blutprodukten) sind als unabhängige Risikofaktoren für eine SSI anzusehen [317, 318].

Vermeidung akzidenteller Hypothermie. Mit Ausnahme therapeutisch oder protektiv erwünschter Hypothermie ist eine akzidentelle Hypothermie insbesondere bei kolorektalen Operationen zu vermeiden [62, 319-324]. Die NICE-Guideline [62] und die WHO [40] empfehlen die Gewährleistung der Normothermie; gemäß NICE-Guideline bei Operationen mit einer OP-Dauer von mindestens 60 $\min$.

\section{Korrektur metabolischer Abweichun-} gen bei elektiven Operationen. Bei der Etablierung der „Fast-Track“-Konzepte hat sich die Erkenntnis durchgesetzt, dass mehrtägiges Fasten vor und nach viszeralchirurgischen Operationen zu vermeiden ist. Mangelernährung ist besonders für die Prognose nach Organtransplantation sowie für die postoperative Morbidität alter Menschen relevant und bei aufschiebbaren Operationen zwischen 7-14 Tagen präoperativ auszugleichen [325]. Inwieweit dieses Prinzip bei Tumorerkrankungen nutzbar ist, hängt von den individuellen Gegebenheiten ab. Die Europäische Gesellschaft für Klinische Ernährung und Metabolismus empfiehlt als Parameter für das Prä-Screening von Risikopatienten das Vorliegen eines Körpermassenindex (BMI) unter $20 \mathrm{~kg} / \mathrm{m}^{2}$, eines Gewichtsverlusts innerhalb der letzten 3 Monate, reduzierte Nahrungsaufnahme in der letzten Woche und schwere Erkrankung [325]. Bei Diabetes mellitus wird prä- und postoperativ die engmaschige Kontrolle des Blutglukosespiegels mit Vermeidung von Werten über $200 \mathrm{mg} / \mathrm{dl}$ bzw. über $11,1 \mathrm{mmol} / \mathrm{l}$ empfohlen [40, 326, 327]. Zum präventiven Einfluss der postopera- tiven Kontrolle des Diabetes mellitus ist die Datenlage widersprüchlich [328, 329].

Probiotika. Es gibt Hinweise darauf, dass der prä- und postoperative Einsatz von Probiotika je nach Eingriff zur Reduktion des SSI-Risikos beitragen kann [330-338].

\subsection{Bauliche Bedingungen}

Allgemein. Der infektionspräventive Effekt der traditionell entstandenen baulichen Vorgaben für OP-Abteilungen (Abtrennung gegenüber der übrigen Klinik bzw. Praxis, räumliche Gliederung innerhalb der Abteilung, Gliederung und Zuschnitt der Räumlichkeiten, leicht zu reinigende horizontale Flächen usw.) ist nicht durch vergleichende Untersuchungen belegt und ergibt sich meist aus grundsätzlichen hygienischen Überlegungen und der damit verbundenen Zweckmäßigkeit.

Raumlufttechnische Anlagen (RLTA). Raumlufttechnische Anlagen haben die Funktion: (i) Außenluft technisch aufzubereiten (Erwärmen, Kühlen, Be- und Entfeuchten, Filtern) und den zu klimatisierenden OP-Räumen zuzuführen, (ii) belastete Luft (Mikroorganismen, Partikel und Aerosole, Narkosegase, chirurgischer Rauch, Geruchsstoffe) aus den Räumen abzuführen, und (iii) letztere ggf. wieder aufzubereiten, soweit sie rückgeführt wird. Inwieweit Nebenräume mit eigener Raumlufttechnik ausgestattet oder durch Überströmung belüftet werden, hängt von den örtlichen Gegebenheiten ab. Die Druckverhältnisse müssen bei Überströmung so gestaltet sein, dass im Vergleich zu den Nebenräumen im OP-Saal ein Überdruck gegeben ist. Es gibt Hinweise darauf, dass Geräte mit eigenständiger Lüftung, die im OP-Raum selbst aufgestellt sind, dort zu einem zusätzlichen Eintrag von Mikroorganismen führen können [339-341]. Für Operationen mit geringerem Risiko (s. 4.4) besteht die Alternative einer ausreichenden Fensterlüftung zwischen den Operationen, sofern der Eintrag von Verunreinigungen von außen verhindert wird (Fliegenfenster), so dass die Installation einer RLTA dort nicht notwendig ist.
Laminar Air flow (LAF)/turbulenzarme Verdrängungsströmung (TAV). Grundsätzlich kommt einem eventuellen Erregereintrag aus der Luft im Rahmen von Operationen eine nachrangige Bedeutung in der Manifestation einer SSI zu. Unter den aktuell verfügbaren Techniken bietet sich für die Versorgung mit partikelarmer und keimarmer Luft - wegen der schnellen Verdrängung und der starken Verdünnung eventuell belasteter Luft die Technik des Laminar Air flow (LAF) bzw. der turbulenzarmen Verdrängungsströmung (TAV) an: Es kann als gesichert angesehen werden, dass durch Zufuhr bakterienfrei filtrierter Luft in Laminar flow-Technik bzw. mittels turbulenzarmer Verdrängungsströmung die mikrobielle Luftbelastung reduziert werden kann [79, 342-349]. Die Effekte der LAF gegenüber turbulenter Mischlüftung sind in Bezug auf die signifikant höhere Reduktion der Erreger- und Partikellast im Schutzbereich (OP-Feld, sterile Tische) und im Raumhintergrund unter definierten Bedingungen in zahlreichen Studien nachgewiesen [183, 222, 342, 350-358]. Eine Benutzung von Helmen mit Luftabsaugung (zusätzlich zu TAV/LAF) hat offenbar keinen eigenständigen zusätzlichen und nachweisbaren Effekt bezüglich eines Erregereintrags [359].

Ein Nachweis dafür, dass es über die Reduktion der mikrobiellen Luftbelastung auch zu einer Reduktion der SSI käme, konnte nicht geführt werden [360]. In älteren prospektiv kontrollierten Studien war durch RLTA mit LAF ein infektionsprophylaktischer Einfluss nachweisbar, welcher sich jedoch teilweise mit dem Einfluss einer gleichzeitig etablierten PAP überlagerte [361-363]. In neueren retrospektiven kontrollierten Studien konnte kein protektiver Einfluss von LAF bzw. TAV im Vergleich zu turbulenter Mischlüftung (TML) gezeigt werden [157, 364-368]. Alle einschlägigen aktuellen Studien sind durch Limitationen gekennzeichnet: Zum Teil ist unbekannt, in welchem Ausmaß sich sterile Flächen außerhalb des TAV-Schutzbereichs befanden; orthopädische Spätinfektionen sind nicht erfasst $[369,370]$.

Getrennte OP-Abteilungen. Weist et al. fanden 1988 nur an patientennahen Oberflächen Hinweise auf eine unterschiedli- 
che Erregerbelastung bei „septischen“ vs. „aseptischen“ Eingriffen [371]. Eine jüngere Beobachtungsstudie konnte bei allgemeinchirurgischen Eingriffen der Kontaminationsklassen I und II vs. Kontaminationsklasse IV keine unterschiedliche Belastung von Luft oder Oberflächen finden [372]. Angaben zu SSI-Raten werden jeweils zu dieser Frage nicht gemacht. Mithin ergibt sich bislang kein Nachweis dafür, dass eine Trennung der OP-Räume nach Kontaminationsklassen („septischer OP-Saal") das SSI-Risiko senken kann.

Bauliche Bedingungen - wissenschaftliche Evidenz und Stellenwert. Zusammenfassend liegen für einen Großteil der Empfehlungen, welche heute bezüglich der baulichen Bedingungen einer OP-Abteilung zu geben sind (s. nachstehend 4.3), keine belastbaren quantifizierbaren Nachweise zum Nutzen der jeweiligen Einzelmaßnahme vor.

Der Stellenwert baulicher Bedingungen von OP-Einheiten für die Vermeidung von SSI ergibt sich vielmehr ergänzend aus einem anderem Zusammenhang: Die medizinische, funktionale und organisatorische Komplexität, durch die Operationen vielfach und zunehmend gekennzeichnet sind, macht nicht nur aseptisches Arbeiten an sich schwer; sie erhöht zudem das Risiko anderer (nicht-hygienischer) Fehler mit der möglichen Folge einer SSI (siehe 2.2). Reduktion funktionaler Komplexität trägt somit auf unterschiedlichen Wegen zur SSI-Prävention bei - auch ohne dass sich dies in mikrobieller Belastung von Luft, Flächen oder Wunden nachweisen lässt. Dass ungünstige räumliche Bedingungen (bei sonst unveränderten Umständen) zu vermehrten Risiken bzw. ungünstigeren Ergebnissen führen, ist für andere Funktionsbereiche belegt $[373,374]$.

Hieraus ableitend wird unter $4.3 \mathrm{emp}$ fohlen werden: Je vielfältiger, risikobehafteter und komplexer die Operationen in ihrer Art sind, je größer der bei einer Operation verwendete „Gerätepark“ ist, je vielfältiger die bei einer Operation gleichzeitig ablaufenden Prozesse sind, je vielfältiger die in einer OP-Abteilung nebeneinander stattfindenden Operationen und je komplexer sie sind, umso eher sollte Gebrauch gemacht werden von den verhal- tens-unabhängigen baulichen Möglichkeiten der Infektionsprävention.

Neben einem ausreichenden Flächenangebot selbst ist eine der Möglichkeiten der Reduktion funktionaler Komplexität die Zonierung einer OP-Abteilung: Räume oder Raumgruppen mit zahlreichen kurzdauernden Operationen (hohe Wechselfrequenz) vs. solche mit wenigen langdauernden Operationen. Räume oder Raumgruppen mit hoher Personalfluktuation vs. solche mit minimalem und konstantem Personalbedarf, etc. Von der Möglichkeit, größere OP-Abteilungen in Zonen zu organisieren, kann mithin nicht nur unter dem Aspekt mikrobieller Belastung Gebrauch gemacht werden [375], sondern gleichermaßen unter dem Aspekt der „Reduktion von funktionaler Komplexität“.

\subsection{Postoperative Betreuung}

Postoperativ gilt es, eine sekundäre Besiedlung etwa noch offener (Operations-) Wunden und/oder einer einliegenden Drainage sowie eine Kontamination anderer Patienten zu vermeiden. Sobald die Operationswunde trocken und geschlossen ist, und etwaige Drainagen entfernt sind (s. 3.1), ergeben sich in der Regel keine über die Basishygiene hinausgehenden hygienischen Anforderungen. Etwaige Infektionszeichen, die nach diesem Zeitpunkt auftreten, sind regelhaft auf eine vor oder während der Operation stattgehabte Inokulation zurückzuführen.

Vor diesem Hintergrund ist es erklärlich, warum der Versuch einer nachträglichen Antiseptik der Wunde bzw. Wundumgebung in der Regel ohne Effekt auf die Infektionsrate bleibt [376-380]. Grundsätzlich könnte der im OP-Saal angelegte Verband bis zur Wundheilung belassen werden [12, 381-384], sofern keine sonstigen Hinweise auf eine Wundheilungsstörung bestehen. Anhaltend sezernierende primär verschlossene Wunden bedürfen einer besonderen Sorgfalt [379, 385, 386].

\subsection{Einbeziehung des Patienten in die Infektionsprävention}

Der Patient ist potentieller Empfänger und auch potentieller Überträger von nosokomialen Erregern. Insofern ist es sinn- voll, den Patienten über für ihn relevante Basismaßnahmen zur Infektionsprävention aufzuklären [387], ihn ggf. auf freiwilliger Basis in anonymisierter Form in die Evaluation ausgewählter Hygienemaßnahmen einzubeziehen [388]. Zur Aufklärung eignen sich kurzgefasste Informationen, Poster und der Patientenfernsehkanal. Wenn dem Patient vermittelt wurde, was mit ihm geschieht und was er selbst zu seinem Schutz beitragen kann, wird die Patientenzufriedenheit erhöht und die Compliance in Bezug auf die Krankheitsbewältigung verbessert. Dieser Zusammenhang konnte bereits 1983 im Bereich der Medikamenteneinnahme nachgewiesen werden [389].

Da die Hände Hauptüberträger nosokomialer Infektionserreger sind [130], empfiehlt es sich, in Anlehnung an die von der WHO für die Mitarbeiter empfohlenen „Fünf Momente“ der Händedesinfektion analog folgende 5 Momente für die Händedesinfektion des Patienten in den Mittelpunkt zu stellen: Händedesinfektion bei Betreten und bei Verlassen des Patientenzimmers, vor der Esseneinnahme, vor und nach Kontakt mit der eigenen Wunde, mit Schleimhäuten oder vor Betreten von Risikobereichen sowie Händewaschen nach dem Toilettengang. Ergänzt werden die Indikationen zur Händedesinfektion durch den Hinweis der Vermeidung unnötiger Kontakte mit Oberflächen und mit anderen Patienten im Krankenhaus. Falls dies unvermeidbar ist, wird die anschließende Händedesinfektion empfohlen.

\subsection{Surveillance}

Daten aus Surveillance-Systemen aus verschiedenen Ländern haben gezeigt, dass die regelmäßige Teilnahme an einem nationalen Surveillance-System und das Feedback der eigenen Daten von SSI zusammen mit nationalen Referenzdaten zu einer signifikanten Reduktion der Rate von SSI von $25 \%$ bis $65 \%$ führen [390-395].

Jede operative Abteilung bzw. jedes ambulante OP-Zentrum muss sich im Rahmen der gesetzlich verpflichtenden Qualitätssicherung und nach Vorgaben des Infektionsschutzgesetzes sowie landesspezifischer Gesetze an der Surveillance der SSI beteiligen, insbesondere in Bezug auf die wichtigsten Indikatorope- 
rationen, die in dieser Abteilung durchgeführt werden. Für die Beurteilung der möglichen SSI sollen die Definitionen des NRZ für Surveillance von nosokomialen Infektionen bzw. des RKI [396] verwendet werden, um Vergleichbarkeit mit nationalen Referenzdaten zu gewährleisten. Wenn möglich, sollte eine Risikoadjustierung der Infektionsraten durchgeführt werden. Die Surveillance-Daten sollen regelmäßig (mindestens einmal pro Jahr) mit den Mitarbeitern, die die Patienten prä-, peri- und postoperativ behandeln und pflegen, besprochen und bewertet werden, daraus sind Schlussfolgerungen abzuleiten ( $\$ 23$ IfSG). Sie werden zudem Gegenstand der verpflichtenden externen gesetzlichen Qualitätssicherung und des Qualitätsberichts (\$137 SGB V).

\subsection{Mitarbeiterschulung}

Die regelmäßige Vermittlung des in die hauseigenen Regularien umgesetzten einschlägigen Wissens ist auch in der Prävention von SSI unverzichtbar. An zahlreichen einzelnen Beispielen konnte nachgewiesen werden, dass sich die „Protokolltreue", d.h. das personalseitige Einhalten der vereinbarten Hygienevorgaben durch Schulungsmaßnahmen, verbessern lässt, zum Beispiel im Bereich der Händehygiene, der Antibiotikaprophylaxe, des Verhaltens im OP oder der OP-Technik [287, 397-401].

\subsection{Bündelstrategie}

Für die Prävention von SSI hat es sich als effektiv erwiesen, besonders wichtige Maßnahmen zu einem Maßnahmenbündel zusammenzufassen (Bündelstrategie), das Bündel zu trainieren und dessen Einhaltung in Form einer Selbstkontrolle mittels Checkliste zu überwachen [402-404], weil dadurch die Compliance der Durchführung verbessert wird [352]. Dabei waren Maßnahmen der meisten Bündel PAP, adäquate Haarentfernung, Kontrolle des Blutglukosespiegels und Normothermie [405]. In Anbetracht des hohen Stellenwerts sind auch der Einschluss der standardisierten präoperativen Hautantiseptik, sowie das präoperative risikobasierte S. aureus-Screening und ggf. -Sanierung sinnvoll in einem Maßnahmenbündel.
Das Problem besteht dabei nicht so sehr in der Formulierung der als notwendig angesehenen infektionspräventiven Maßnahmen, sondern vielmehr darin, das konkrete alltägliche Handeln der klinisch Tätigen nachhaltig zu beeinflussen [406]. Um überhaupt einen verhaltenssteuernden Effekt erzielen zu können, sollte die Zahl der in einem „Bündel“ vermittelten Maßnahmen klein und überschaubar gehalten werden, die einschlägige Schulung sollte sich über eine längere Zeit auf diese wenigen Maßnahmen fokussieren und deren Einhaltung nachdrücklich einfordern. Die Bedeutung positiver oder negativer Vorbilder darf nicht unterschätzt werden. Unlogische bzw. eindeutig nicht erbringbare Verhaltensformen sollten nicht gefordert werden [399, 407].

\section{Empfehlungen zur Vermeidung von SSI}

In der Prävention von SSI ergänzen sich hygienegerechtes Verhalten, begleitende perioperative Maßnahmen und räumlich-bauliche Voraussetzungen. Weder ein verbindlicher Verhaltenskodex noch ein hygienisch-infektiologisch begründbares Bauprogramm lassen sich aus dem Begriffspaar ambulant/stationär ableiten. Entscheidend für das Muster der zu ergreifenden Präventionsmaßnahmen ist das SSI-Risiko der jeweiligen Operationen. Dies ist abzuschätzen (siehe 4.4).

Für die nachstehenden Empfehlungen gilt:

- Die nachstehenden Empfehlungen

(4.1 bis 4.3) gelten für die Mehrzahl der offenen Operationen. Außerdem gelten sie für diejenigen interventionellen Operationen, bei denen es gehäuft bzw. vorhersehbar zum Verfahrenswechsel zur offenen Operation kommt.

- Bei interventionellen Operationen sowie gewissen offenen Operationen mit geringem SSI-Risiko sind Varianten (vor allem bezüglich der räumlichen Gestaltung) möglich (siehe 4.4).

\subsection{Präoperativ und intraoperativ}

\section{Die Kommission empfiehlt}

- soweit möglich, präoperativ bestehende Infektionen beim Patien- ten zu erkennen und zu behandeln (Kat. IB).

- bei kardiochirurgischen und orthopädischen Operationen bei Patienten mit nasaler Kolonisation mit S. aureus eine präoperative Dekolonisation der Nase mit Mupirocin-Nasensalbe $2 \%$ allein oder in Kombination mit einer Körperwaschung mit Chlorhexidingluconat durchzuführen (Kat. IB). Alternativ kann der Einsatz von Antiseptika für die Nase und die Haut bei diesen Patienten sinnvoll sein (Kat. II).

- diese Behandlung auch bei anderen Operationsarten mit einem hohen Anteil von S. aureus als Erreger von Wundinfektionen für S. aureus-Carrier vorzunehmen (Kat. II).

- die präoperative Verweildauer so kurz wie möglich zu halten (Kat. II).

- vor kolorektalen Operationen eine mechanische Darmentleerung in Verbindung mit oraler Antibiotikagabe durchzuführen (Kat. II).

- die Haut des Operationsgebietes des Patienten außerhalb der Operationsabteilung gründlich zu reinigen (Kat. II). Haare im Operationsgebiet mittels Kürzen der Haare und nicht durch Rasur zu entfernen (Kat. IA). Der Zeitpunkt für das Kürzen mittels Clipping kann unter arbeitsorganisatorischen Gesichtspunkten gewählt werden (Kat. II).

- allen Personen, die die Operationsabteilung betreten wollen, in der Personalumkleide ihre gesamte Oberbekleidung einschließlich der Schuhe abzulegen und im reinen Bereich nach hygienischer Händedesinfektion keimarme (im Desinfektions-Waschverfahren aufbereitete) Bereichskleidung (z. B. Hose, Hemd/Kittel, OPSchuhe) anzulegen (Kat. II). Bei zu erwartender Durchfeuchtung flüssigkeitsdichte Schuhe zu verwenden (unter dem Aspekt des Personalschutzes) (Kat. IV). Keinen Schmuck, Ringe oder Uhren an Unterarmen und Händen zu tragen (Kat. II) bzw. andere gefahrenträchtige Schmuckstücke sowie keine künstlichen Fingernägel und keinen Nagellack (Kat. IB).

- vor Betreten des Operationsraumes einen Mund-Nasen-Schutz (MNS) und 
Haarschutz anzulegen (Kat. IB). Haarschutz und Mund-Nasen-Schutz müssen sämtliche Bart- und Kopfhaare sowie Mund und Nase vollständig bedecken, ebenso eine ggf. aus persönlichen Gründen zusätzlich getragene Kopfbedeckung (Kat. II). Den MNS vor jeder Operation und bei sichtbarer Verschmutzung oder Durchfeuchtung zu erneuern (Kat. II). Wurde der MNS entfernt, so wird er durch einen neuen MNS ersetzt. Anschließend eine hygienische Händedesinfektion durchzuführen (Kat. IB).

- den OP-Bereich mit sauberen Händen zu betreten. Nach Händewaschung und vor einer chirurgischen Händedesinfektion die Hände zu trocknen (Kat. II).

- die chirurgische Händedesinfektion vom OP-Team einschließlich der instrumentierenden Mitarbeiter durchführen zu lassen (Kat. IB).

- als Mittel der Wahl für die chirurgische Händedesinfektion arzneilich zugelassene alkoholbasierte Präparate anzuwenden (Kat. IB); der Zusatz eines remanent wirksamen Antiseptikums ist nicht erforderlich und erhöht das Risiko von Nebenwirkungen (Kat. II).

- dem Operationsteam im OP-Raum nach der chirurgischen Händedesinfektion das Anlegen eines sterilen Operationskittels und anschließend steriler Handschuhe (Kat. IB). Bei Operationen, die erfahrungsgemäß mit einer vermehrten Läsion von Handschuhen einhergehen, zwei Paar Handschuhe zu tragen (Kat. II). Nach der manuellen Handhabung von scharfkantigen Implantaten oder Explantatbestandteilen oder der Entfernung von Zementbruchstücken (z. B. bei Endoprothesenwechsel) die Handschuhe zu wechseln (Kat. IB), ebenso unmittelbar vor Implantation einer Gelenkendoprothese (Kat. II).

- als Schutzkittel als Medizinprodukt zertifizierte sterile OP-Kittel aus Einweg- oder Mehrwegmaterial zu verwenden. Bei Operationen mit geringem Flüssigkeitsanfall flüssigkeitsabweisende Kittel („low performance") und bei erwartet hohem Flüssigkeitsanfall und bei bekann- ter Infektion des Patienten mit hoher Personalgefährdung (z. B. HIV, HCV) flüssigkeitsdichte Kittel („high performance") zu verwenden (Kat. IB). Bei Operationen, bei denen mit dem Auftreten von Aerosolen/Sekretspritzern zu rechnen ist, Schutzbrillen oder Schutzschilde zu tragen (Kat. II/IV). - dem übrigen OP-Personal (z. B. Springer): Eine Kontamination der Hände mit potentiell kontaminierten Materialien oder Flüssigkeiten durch das Tragen von Schutzhandschuhen zu vermeiden; bei akzidentieller Verschmutzung eine hygienische Händedesinfektion durchzuführen, ggf. mit anschließendem Händewaschen (Kat. IA). Nach Berühren kontaminierter Gegenstände (z. B. Manipulation am MNS) ebenso wie vor allen Maßnahmen am Patienten eine hygienische Händedesinfektion durchzuführen (Kat. IA).

- nach Toilettenbesuch eine Händewaschung durchzuführen (Kat. IB). Ob auch neue Bereichskleidung angelegt werden muss, ist eine ungelöste Frage (Kat. III). Vor Wiederaufnahme der Arbeit eine hygienische Händedesinfektion durchzuführen.

- im Operationsraum eine gründliche Antiseptik der Haut des Operationsgebietes mit einem Alkohol-basierten Hautantiseptikum durchzuführen (Kat. IA). Durch Zusatz eines remanent wirkenden Antiseptikums wird eine über die Wirkung von Alkohol hinaus anhaltende Wirkung erreicht (Kat. IB). Welchem Wirkstoff der Vorzug zu geben ist, ist derzeit ungeklärt (Kat. III). Zur Antiseptik auf Schleimhäuten und dem Auge für den jeweiligen Anwendungsbereich zugelassene Antiseptika zu verwenden. Während der deklarierten Einwirkzeit das Hautareal satt benetzt und feucht zu halten, bevorzugt durch mehrfaches Aufbringen des Antiseptikums. Dabei auf die längere Einwirkzeit auf talgdrüsenreichen Hautarealen zu achten (Kat. II). Ferner darauf zu achten, dass der Patient nicht in einer Flüssigkeitsansammlung des Hautantiseptikums zu liegen kommt, da dies zu Hautnekrosen und zur Verpuffung führen kann (Kat. II).
- nach der Antiseptik des OP-Feldes die Umgebung des Operationsgebietes steril abzudecken (Kat. IB). Bei Operationen, bei denen ein Durchfeuchten nicht auszuschließen ist, flüssigkeitsundurchlässige Abdeckungen zu verwenden (Kat. IB). Die Verwendung von nicht antiseptisch imprägnierten Inzisionsfolien wird nicht empfohlen (Kat. IB). OP-Ringfolien bieten nicht bei allen Operationen nachweisbare Vorteile in Bezug auf Prävention von SSI (Kat. II).

- während der Operation die Anzahl der im Operationsraum Anwesenden, deren Fluktuation und deren Sprechen auf ein Mindestmaß zu begrenzen, die Türen des Operationsraumes, soweit möglich, geschlossen zu halten (Kat. II).

- falls es während der Operation zur Kontamination des Operationskittels, des Sterilfeldes oder der Operationshandschuhe kommt, Kittel bzw. Handschuhe zu wechseln bzw. das Operationsfeld neu abzudecken, unsteril gewordene Instrumente $\mathrm{zu}$ wechseln (Kat. IB). Den Wechsel von Operationskittel oder Operationshandschuhen abseits vom Operationsfeld vorzunehmen (Kat. IB).

\section{Die Kommission stellt fest}

- Auf die Wahl zwischen Elektrokauter und Skalpell haben infektionspräventive Überlegungen keinen Einfluss (Kat. II).

- Eine passagere Hyperoxygenierung beim Patienten bleibt bezüglich der Infektionsvermeidung ohne durchgängig nachweisbaren Vorteil (Kat. III).

- Antiseptisch beschichtetes Nahtmaterial hat nur bei sehr hohen AusgangsSSI-Raten, bei Operationen der Kontaminationsklassen III und IV sowie bei multimorbiden Patienten einen die Infektionsgefahr reduzierenden Effekt (Kat. II).

- Die Versiegelung der Haut bietet gegenüber der konventionellen Antiseptik und Abdeckung keinen nachweisbaren Vorteil (Kat. III). 


\section{Die Kommission empfiehlt}

- die Indikation zu einer systemischen antibiotischen Prophylaxe eingriffsspezifisch zu stellen (Kat. IA). Mehrfachdosierungen während der Operation ausschließlich bei sehr lang dauernden Operationen vorzunehmen (Kat. IA). Auf eine verlängerte Antibiotikagabe nach OP-Ende zu verzichten (Kat. IA).

- nur sachgerecht aufbereitete Medizinprodukte zur Anwendung kommen $\mathrm{zu}$ lassen (s. MPG und MPBetreibV) (Kat. IV).

- nach Ende der Operation Instrumente und andere aufzubereitende Materialien im Operationsraum bedarfsweise mit manueller Vorbereitung in geeignete Behältnisse abzulegen. Diese werden geschlossen zur ZSVA bzw. zum Übergaberaum für unreine Güter verbracht (Kat. IV). Hierbei wird insbesondere auf eine gefahrlose Entsorgung spitzer Gegenstände geachtet (Kat. IV). Benutzte Operationshandschuhe und Operationskittel im Operationsraum abzulegen.

- nach jeder Operation die patientennahen Flächen, alle sichtbar kontaminierten Flächen sowie der gesamte begangene Fußboden des Operationsraumes desinfizierend zu reinigen (Kat. II). Nach Abtrocknen des Desinfektionsmittels kann der Operationsraum wieder begangen werden (Kat. II).

- in den Waschzonen die benutzten Armaturen und Waschbecken in regelmäßigen Abständen desinfizierend zwischen zu reinigen; in den übrigen Nebenräumen erfolgt eine desinfizierende Zwischenreinigung bei sichtbaren Verschmutzungen (Kat. II).

- generell bei Kontamination mit Bakteriensporen oder unbehüllten Viren sporozid bzw. viruzid wirksame Präparate auszuwählen (Kat. IB).

- wenn nach vorangegangener Operation die Flächen-Zwischendesinfektion abgeschlossen ist, mit der Vorbereitung der folgenden Operation zu beginnen. Die benötigten sterilen Instrumente und Materialien im Operationssaal von einer steril bekleideten Person auf steril abgedeckten Tischen herzurichten und anschließend bis zum Beginn der eigentlichen Operation mit sterilen Tüchern abzudecken (Kat. II). Diese Tätigkeit durchzuführen, bevor andere Aktivitäten im OP-Saal stattfinden (zum Beispiel Lagerung, Narkoseeinleitung).

- für das Herrichten steriler Instrumente im Vorlauf ausschließlich einen gesonderten Raum zu benutzen (s. nachstehend „Instrumentenvorbereitung") (Kat. II).

- am Ende des täglichen OP-Programms alle Fußbodenflächen und potenziell kontaminierte Flächen in allen Räumen der Operationsabteilung einer desinfizierenden Reinigung zu unterziehen (Kat. II). Auch Dokumentationshilfsmittel (z. B. DV-Einrichtungen) bedürfen einer regelmäBigen Desinfektion (Kat. II).

- für das Personal: die Operationsabteilung durch die Personalumkleide $\mathrm{zu}$ verlassen und dort die gesamte Bereichskleidung abzulegen.

- die Anwendung von Hautschutz- und Hautpflegepräparaten im Hautschutzplan festzulegen (Kat. II/IV).

\subsection{Postoperativ}

\section{Die Kommission empfiehlt}

\section{Postoperative Wundbetreuung:}

- die OP-Wunde am Ende der Operation mit einer sterilen Wundauflage abzudecken. Der erste Verbandwechsel nach etwa 48 Stunden durchzuführen, sofern nicht Hinweise auf eine Komplikation zu einem früheren Verbandwechsel Anlass geben (Kat. IB). Ist danach die Wunde trocken und verschlossen, kann unter hygienischen Aspekten auf eine erneute sterile Wundabdeckung verzichtet werden (Kat. IB). Die regelmäßige ärztliche Inspektion der Wunde ist Teil einer vollständigen und sachgerechten Nachsorge. Drainagen (unter hygienischem Aspekt) möglichst frühzeitig zu entfernen (Kat. II); der Zeitpunkt der Entfernung ist chirurgisch determiniert.

- wenn sich klinische Verdachtsmomente einer SSI ergeben, diese zeitnah und mit Dringlichkeit auszuräumen bzw. zu verifizieren (Kat. IB).
Organisation:

- Verbandwechsel oder die Entfernung von Nahtmaterial bzw. von Drainagen mit Verbandwagen oder mit Tablettsystem durchzuführen. Die Benutzung unterschiedlicher Verbandwagen für aseptische und infizierte Wunden ist nicht erforderlich - entscheidend ist, den Wagen grundsätzlich vor Kontamination zu schützten. Im Übrigen sind bei diesen Manipulationen die Regeln der Basishygiene einzuhalten (Kat. II).

- dem Patienten zusätzlich zur erforderlichen Aufklärung über die mit der $O P$ verbundenen Risiken Basisinformationen über die Möglichkeiten zu vermitteln, durch hygienebewusstes Handeln und rechtzeitige Information über einen abweichenden Heilungsverlauf einer SSI vorzubeugen (Kat. II).

\section{Die Kommission stellt fest}

- Eine Surveillance der SSI ist verpflichtend (Kat. IA/IV).

\subsection{Räumliche Gestaltung (alles Kat. II)}

Die hygienischen Anforderungen an die räumliche Gestaltung von Operationsabteilungen richten sich nach der jeweiligen Aufgabenstellung. Durch eine adäquate Raumplanung wird eine sinnvolle Ablauforganisation erleichtert und sichergestellt, dass bei allen Operationen (unabhängig von ihrer fachlichen $\mathrm{Zu}$ ordnung und ihrem Kontaminationsgrad) mit ausreichend Platz hygienisch einwandfreies Arbeiten unter Berücksichtigung der jeweiligen medizintechnischen Ausrüstung und des Personalaufwands möglich ist. Für OP-Abteilungen mit stark heterogenem Leistungsaufkommen empfiehlt sich eine Zonierung (siehe oben). 


\section{Räume und Flächen}

Der funktionell abgetrennte OP-Bereich enthält:

- Einen oder mehrere Operationsräume mit je einem Operationstisch

- Fläche oder Raum für Narkoseeinleitung und Patientenvorbereitung

- Fläche oder Raum für Narkoseausleitung und unmittelbare Patientennachsorge

- Fläche oder Raum für Händedesinfektion

- Lagerräume für saubere Geräte, für Sterilgut und andere Vorräte

- Mitarbeiteraufenthaltsraum

- Raum für die Aufbereitung unreiner/ benutzter Geräte (unreiner Arbeitsraum)

- Raum zur Lagerung von Reinigungsutensilien

- Schleusensysteme

- Personalschleuse,

- Patientenübergaberaum bzw. -übergabefläche mit Bettenabstellplatz

- Übergaberaum für reine Güter

- Übergaberaum für unreine Güter

- Aufwachraum/-bereich

- Abstellplatz für OP-Tische

- Raum für Dokumentations- und Verwaltungsaufgaben

- Raum oder Fläche zur Händewaschung

- ggf. Vorbereitungsraum für Instrumentiertische

- ggf. Patientenumkleideraum

\section{Die Kommission empfiehlt}

Operationsräume:

- dass Operationsräume in sich abgeschlossen sind und möglichst wenige, aber ausreichend dimensionierte Türen haben. Sofern Bodeneinläufe innerhalb eines Operationsraumes vorhanden sein müssen, Techniken zu wählen, die eine Kontamination der Umgebung verhindern.

Zusammenfassung von Räumen und Flächen:

- Räume bzw. Flächen für folgende Funktionen können jeweils für mehrere OP-Räume zusammengefasst werden: Narkoseeinleitung, Patientenvorbereitung, Narkoseausleitung, Patientennachbetreuung, Händewaschung, Händedesinfektion. Auch andere Räume können zusammengefasst werden, soweit dies unter dem Aspekt der Infektionsprävention und der Funktion möglich ist.

\section{Instrumentenvorbereitung:}

- falls Instrumentiertische nicht im OP vorbereitet werden, sondern in einem gesonderten Raum (Vorbereitungsraum für Instrumentiertische), dort die gleichen hygienischen Bedingungen (z.B. Lüftungsbedingungen) wie im OP zu gewährleisten.

Personalumkleideraum (Personalschleuse):

- in der Personalumkleide die reine und unreine Seite mindestens funktionell zu trennen. Bei der Wegeführung eine Kreuzung zu vermeiden. In der unreinen Seite ausreichend Fläche/Schränke für die Ablage der Stationskleidung und Sammelbehälter für benutzte Bereichskleidung, weiterhin Waschbecken, WC-Anlagen und ggf. Duschen vorzuhalten. In der reinen Seite Lagermöglichkeiten zur geschützten Lagerung des Tagesbedarfs an reiner Bereichskleidung sowie Möglichkeiten zur Händedesinfektion vorzuhalten.

Patientenübergaberaum/Patientenübergabefläche:

- in der Patientenübergabefläche den Patienten umzulagern und zwar bevorzugt mittels Umbetthilfen. In unmittelbarer Nähe ausreichend Warteplätze für Betten vorzuhalten. Bei Operationsbetrieb für ambulante $\mathrm{Pa}$ tienten zusätzlich Patientenumkleiden vorzuhalten.

- den Aufwachraum baulich bevorzugt an den Übergang von der OP-Abteilung zum übrigen Krankenhaus zu legen und durch funktionelle und organisatorische Maßnahmen einer Durchbrechung des Prinzips der Personalschleuse entgegenzuwirken.

\section{Materialversorgung/-entsorgung:}

- für die Materialversorgung einen Raum oder eine Zone vorzuhalten, wo die Güter ohne Transportverpackung angeliefert werden. Entsprechend für die Entsorgung einen separaten Entsorgungsraum vorzuhalten. Innerhalb der Operationsabteilung reine Güter (Sterilgüter, Medikamente, aufbereitete Geräte usw.) in speziellen Räumen oder in geeigneten Behältnissen auf dafür ausgewiesenen Flächen zu bevorraten. Unreine Güter (Schmutzwäsche, Abfälle, etc.) im entsprechenden gesonderten Übergaberaum zu lagern. Für Leihinstrumente ist ausreichend Platz vorzuhalten.

- in der gesamten Operationsabteilung in angemessener Anzahl bedarfsgerecht verteilte Spender für die Händedesinfektion und Untersuchungshandschuhe vorzuhalten.

\section{Oberflächen:}

- die Oberflächen der Räume und betrieblichen Einbauten (z. B. Türen, Regalsysteme, Lampen) sowie der Geräte so zu beschaffen bzw. so zu positionieren, dass es zu möglichst wenigen Beschmutzungen kommt und sie problemlos gereinigt und desinfiziert werden können. Oberflächen müssen intakt sein ohne dass es z. B. zu Abblätterung (zum Beispiel von Farbe) oder schwer zu reinigenden/desinfizierenden Oberflächen kommt. Gleiches gilt für die Lagerung von Materialien und Geräten.

\section{Lüftung:}

- sofern die OP-Abteilung mit einer raumlufttechnischen Anlage ausgestattet ist, diese regelmäßig zu warten dass sie dem technischen Standard entspricht. In die OP-Räume (und ggf. Vorbereitungsräume für das Herrichten von Instrumentiertischen) wird dreifach gefilterte Luft eingeleitet. Die OP-Säle haben eine Überdruckhaltung im Vergleich zu den Nebenräumen. Geräte mit eigenständigen Lüftungen (z. B. Hypothermiegeräte bei kardio-chirurgischen Operationen) so zu positionieren bzw. zu gestalten, dass von ihnen keine eigene Kontaminationsgefahr ausgeht.

\section{Die Kommission stellt fest}

- Aus der Nutzung von LAF/TAV ergibt sich kein eigener infektionspräventiver Effekt (Kat. II).

- Aus der Trennung „reiner“ und „unreiner" OP-Abteilungen ergibt sich 
kein eigener infektionspräventiver Effekt (Kat. II).

\subsection{Operationen mit geringem SSI-Risiko}

- Operationen mit geringem SSI-Risiko können unter modifizierten räumlichen Bedingungen durchgeführt werden. Entscheidend für die Risikobewertung ist die Beurteilung des postoperativen Infektionsrisikos (soweit vorhanden anhand von Surveillancedaten) und der Bedeutung einer etwaigen SSI. Es wird empfohlen, dass das Risk Assessment für die Zuordnung anhand des geplanten OP-Spektrums gemeinsam vom chirurgischen Fachvertreter und dem beratenden Hygieniker durchgeführt wird. Ein geringes Infektionsrisiko ist z. B. gegeben bei kleinen Eingriffen an der Haut/Subkutis, am Auge, in der Mund-, Kiefer-, Stirnhöhle, Endoskopien von Körperhöhlen, Abzesseröffnung sowie für die interventionellen radiologischen und kardiologischen Eingriffe (außer mit regelhaft erwartetem Verfahrenswechsel). - Für diese Eingriffe können (abweichend von 4.3) die außerhalb des OP-Raums liegenden Nebenräume bzw. deren Funktionen zusammengefasst werden. Bei mobilen Patienten kann die Umlagerung vereinfacht werden. Auf eine RLTA aus infektionshygienischen Gründen kann verzichtet werden. Die desinfizierende Zwischenreinigung der Flächen kann auf die patientennahen Flächen und alle sichtbaren Kontaminationen beschränkt werden.

- Noch geringer ist das Infektionsrisiko bei im Hautniveau liegenden Tumoren oder Fremdkörpern (außer wenn sehr ausgedehnt) sowie bei Verletzungen der Haut oder der Subkutis (außer wenn sehr ausgedehnt). Diese invasiven Maßnahmen können auch in einem Raum durchgeführt werden, der nicht in eine OP-Abteilung integriert ist. Der Raum ist ausreichend groß, seine Oberflächen sind leicht $\mathrm{zu}$ reinigen und zu desinfizieren. Die unter 4.3 beschriebenen räumlichen Funktionen sind dort zusammengefasst. Steriler Schutzkittel, Haarschutz und MNS sind nicht regelhaft erforderlich, das Ausmaß der Sterilabdeckung und die Art der Personalbekleidung richten sich nach der Art der Operation und nach der Größe des Operationsfelds.

Entscheidend für die Ausgestaltung der eine Operation begleitenden organisatorischen Maßnahmen und der baulichen Bedingungen ist das Gesamtrisiko aller Operationen einer Abteilung/Organisationseinheit. Dies wird gemeinsam mit dem Krankenhaushygieniker bewertet. Begleiterkrankungen sowie besondere risikoerhöhende Umstände sind besonders zu berücksichtigen. Die Frage, ob eine Operation "ambulant" oder „stationär“ durchgeführt wird (d.h. mit oder ohne 24-Stunden-Aufenthalt, bzw. ob nach EBM oder DRG-Katalog abgerechnet wird) spielt für die Einschätzung des SSI-Risikos keine Rolle.

Interessenkonflikt. Diese Empfehlungen wurden ehrenamtlich und ohne Einflussnahme kommerzieller Interessengruppen im Auftrag der Kommission für Krankenhaushygiene und Infektionsprävention bearbeitet von Prof. Dr. Martin Hansis (Leiter der Arbeitsgruppe), Prof. Dr. Axel Kramer, Prof. Dr. Wolfram Mittelmeier, Prof. Dr. Matthias Trautmann, Prof. Dr. Martin Exner, Prof. Dr. Martin Mielke und Marc Thanheiser (für das RKI). Die Empfehlung wurde durch die Arbeitsgruppe vorbereitet und nach ausführlicher Diskussion in der Kommission abgestimmt.

\section{Literatur}

1. Kommission für Krankenhaushygiene und Infektionsprävention (KRINKO) (2010) Die Kategorien in der Richtlinie für Krankenhaushygiene und Infektionsprävention - Aktualisierung der Definitionen. Bundesgesundheitsblatt 53(7):754-756

2. Statistisches Bundesamt (2013) Fallpauschalenbezogene Krankenhausstatistik (DRG-Statistik) Operationen und Prozeduren der vollstationären Patientinnen und Patienten in Krankenhäusern - Ausführliche Darstellung - 2012 (URL: https://www.destatis.de/DE/Publikationen/ Thematisch/Gesundheit/Krankenhaeuser/ OperationenProzeduren5231401127014.pdf? blob=publicationFile)

3. Behnke M, Hansen S, Leistner R et al (2013) Nosokomiale Infektionen und AntibiotikaAnwendung. Zweite nationale Prävalenzstudie in Deutschland. Dtsch Arztebl 110:627-633

4. Gastmeier P, Geffers C (2008) Nosokominale Infektionen in Deutschland: Wie viele gibt es wirklich? Eine Schätzung für das Jahr 2006. Dtsch Med Wochenschr 133:1111-1115

5. Mangram AJ, Horan TC, Pearson ML, Silver LC, Jarvis WR (1999) Guideline for prevention of surgical site infection, 1999. Am J Infect Control 27(2):97-134
6. Robson MC (1979) Infection in the surgical patient: an imbalance in the normal equilibrium. Clin Plast Surg 6(4):493-503

7. Hansis ML (1996) Pathophysiology of infection-a theoretical approach. Injury 27(Suppl 3):SC5SC8

8. Eijer $\mathrm{H}$, Hauke $\mathrm{C}$, Arens S, Printzen $\mathrm{G}$, Schlegel U, Perren SM (2001) PC-fix and local infection resistance--influence of implant design on postoperative infection development, clinical and experimental results. Injury 32(Suppl 2):B38-B43

9. Arens S, Hansis M (1998) Implantate in der Unfallchirurgie: Osteosynthese mit Titan. Dtsch Arztebl 95(24):A1516-A1518

10. Cruse PE, Foord R (1973) A five-year prospective study of 23,649 surgical wounds. Arch Surg 107(2):206-210

11. Cruse PJ, Foord R (1980) The epidemiology of wound infection. A 10-year prospective study of 62,939 wounds. Surg Clin North Am 60(1):27-40

12. Kappstein I (2008) Postoperative Wundinfektionen - Ursachen und Prävention. Krankenhhyg up2date 3(01):9-28

13. Uckay I, Harbarth S, Peter R, Lew D, Hoffmeyer $P$, Pittet D (2010) Preventing surgical site infections. Expert Rev Anti Infect Ther 8(6):657-670

14. Rutala WA, Weber DJ (2001) A review of singleuse and reusable gowns and drapes in health care. Infect Control Hosp Epidemiol 22(04):248257

15. Ayliffe GAJ (1991) Role of the environment of the operating suite in surgical wound infection. Rev Infect Dis 13(Suppl 10):S800-S804

16. Reiffel AJ, Barie PS, Spector JA (2013) A multidisciplinary review of the potential association between closed-suction drains and surgical site infection. Surg Infect (Larchmt) 14(3):244-269

17. Nationales Referenzzentrum für Surveillance von nosokomialen Infektionen (NRZ) (2015) KISS Krankenhaus-Infektions-Surveillance-System. Modul OP-KISS. Referenzdaten. Berechnungszeitraum: Januar 2010 bis Dezember 2014 (URL: http://www.nrz-hygiene.de/fileadmin/nrz/ module/op/Referenzdaten_2010-2014)

18. Bonds AM, Novick TK, Dietert JB, Araghizadeh FY, Olson CH (2013) Incisional negative pressure wound therapy significantly reduces surgical site infection in open colorectal surgery. Dis Colon Rectum 56(12):1403-1408

19. Malone DL, Genuit T, Tracy JK, Gannon C, Napolitano LM (2002) Surgical site infections: reanalysis of risk factors. J Surg Res 103(1):89-95

20. Olsen MA, Lock-Buckley P, Hopkins D, Polish LB, Sundt TM, Fraser VJ (2002) The risk factors for deep and superficial chest surgical-site infections after coronary artery bypass graft surgery are different. J Thorac Cardiovasc Surg 124(1):136-145

21. Kao LS, Phatak UR (2013) Glycemic control and prevention of surgical site infection. Surg Infect (Larchmt) 14(5):437-444

22. Okabayashi T, Shima Y, Sumiyoshi T et al (2014) Intensive versus intermediate glucose control in surgical intensive care unit patients. Diabetes Care 37(6):1516-1524

23. Okabayashi T, Nishimori I, Maeda H, Yamashita K, Yatabe T, Hanazaki K (2009) Effect of intensive insulin therapy using a closed-loop glycemic control system in hepatic resection patients: a prospective randomized clinical trial. Diabetes Care 32(8):1425-1427

24. Golden SH, Peart-Vigilance C, Kao WH, Brancati FL (1999) Perioperative glycemic control and the 
risk of infectious complications in a cohort of adults with diabetes. Diabetes Care 22(9):14081414

25. Russo PL, Epi GDC, Spelman DW (2002) A new surgical-site infection risk index using risk factors identified by multivariate analysis for patients undergoing coronary artery bypass graft surgery. Infect Control Hosp Epidemiol 23(7):372-376

26. Hirao M, Tsujinaka T, Imamura $\mathrm{H}$ et al (2013) Overweight is a risk factor for surgical site infection following distal gastrectomy for gastric cancer. Gastric Cancer 16(2):239-244

27. Itani KM, Jensen EH, Finn TS, Tomassini JE, Abramson MA (2008) Effect of body mass index and ertapenem versus cefotetan prophylaxis on surgical site infection in elective colorectal surgery. Surg Infect (Larchmt) 9(2):131-137

28. Yoshimura Y, Kubo S, Hirohashi K et al (2003) Plastic iodophor drape during liver surgery operative use of the iodophor-impregnated adhesive drape to prevent wound infection during high risk surgery. World J Surg 27(6):685-688

29. Dahl RM, Wetterslev J, Jorgensen LN, Rasmussen LS, Moller AM, Meyhoff CS (2014) The association of perioperative dexamethasone, smoking and alcohol abuse with wound complications after laparotomy. Acta Anaesthesiol Scand 58(3):352-361

30. Swenson BR, Camp TR, Mulloy DP, Sawyer RG (2008) Antimicrobial-impregnated surgical incise drapes in the prevention of mesh infection after ventral hernia repair. Surg Infect (Larchmt) 9(1):23-32

31. Kulier A, Gombotz H (2001) Perioperative Anämie. Anaesthesist 50(2):73-86

32. Karpelowsky JS, Millar AJ, van der Graaf N, van Bogerijen G, Zar HJ (2012) Comparison of inhospital morbidity and mortality in HIV-infected and uninfected children after surgery. Pediatr Surg Int 28(10):1007-1014

33. Kigera JWM, Straetemans M, Vuhaka SK, Nagel IM, Naddumba EK, Boer K (2012) Is there an increased risk of post-operative surgical site infection after orthopaedic surgery in HIV patients? A systematic review and meta-analysis. PLOS ONE 7(8):e42254

34. Liu BC, Zhang L, Su JS, Tsun A, Li B (2014) Treatment of postoperative infectious complications in patients with human immunodeficiency virus infection. World J Emerg Med 5(2):103-106

35. Capocasale E, De Vecchi E, Mazzoni MP et al (2014) Surgical site and early urinary tract infections in 1000 kidney transplants with antimicrobial perioperative prophylaxis. Transplant Proc 46(10):3455-3458

36. Galindo Sacristan P, Marfil PA, Osorio Moratalla JM et al (2013) Predictive factors of infection in the first year after kidney transplantation. Transplant Proc 45(10):3620-3623

37. Nakamura T, Mitomi H, Ihara A et al (2008) Risk factors for wound infection after surgery for colorectal cancer. World J Surg 32(6):1138-1141

38. Hirakawa H, Hasegawa $\mathrm{Y}$, Hanai N, Ozawa T, Hyodo I, Suzuki M (2013) Surgical site infection in clean-contaminated head and neck cancer surgery: risk factors and prognosis. Eur Arch Otorhinolaryngol 270(3):1115-1123

39. Penel N, Fournier C, Lefebvre D, Lefebvre J-L (2005) Multivariate analysis of risk factors for wound infection in head and neck squamous cell carcinoma surgery with opening of mucosa. Study of 260 surgical procedures. Oral Oncol Extra 41(3):35-44
40. World Health Organization (WHO) (2016) Global guidelines on the prevention of surgical site infection. Geneva, WHO Document Production Services (URL: http://www.who.int/gpsc/ssiprevention-guidelines/en/)

41. Webster J, Croger S, Lister C, Doidge M, Terry MJ, Jones I (2010) Use of face masks by nonscrubbed operating room staff: a randomized controlled trial. Anz J Surg 80(3):169-173

42. Cho M, Kang J, Kim IK, Lee KY, Sohn SK (2014) Underweight body mass index as a predictive factor for surgical site infections after laparoscopic appendectomy. Yonsei Med J 55(6):16111616

43. Correia MI, Waitzberg DL (2003) The impact of malnutrition on morbidity, mortality, length of hospital stay and costs evaluated through a multivariate model analysis. Clin Nutr 22(3):235-239

44. Kimura Y, Tsujinaka T, Fujitani K et al (2011) A randomized controlled phase III trial to evaluate the effect of preoperative enteral immunonutrition on the surgical site infection after total gastrectomy (OGSG0507). J Clin Oncol 29(4 Suppl 1):74

45. Shibata $Y$ (2011) Efficacy of perioperative immunonutritional support with immune-modulating nutrients for postoperative infection-related complications, such as surgical site infection, in elective gastrointestinal cancer surgery. J Clin Oncol 29(15 Suppl):e19716

46. Fujitani K, Tsujinaka T, Fujita J et al (2012) Prospective randomized trial of preoperative enteral immunonutrition followed by elective total gastrectomy for gastric cancer. Br J Surg 99(5):621-629

47. Okabayashi T, Nishimori l, Sugimoto T et al (2008) Effects of branched-chain amino acidsenriched nutrient support for patients undergoing liver resection for hepatocellular carcinoma. J Gastroenterol Hepatol 23(12):1869-1873

48. Lewis SJ, Egger M, Sylvester PA, Thomas S (2001) Early enteral feeding versus "nil by mouth" after gastrointestinal surgery: systematic review and meta-analysis of controlled trials. BMJ 323(7316):773-776

49. Rädle J, Rau B, Kleinschmidt S, Zeuzem S (2007) Operatives Risiko bei hepatologischen und gastroenterologischen Erkrankungen. Dtsch Arztebl Int 104(26):A1914-A1921

50. Murray BW, Huerta S, Dineen S, Anthony T (2010) Surgical site infection in colorectal surgery: a review of the nonpharmacologic tools of prevention. J Am Coll Surg 211(6):812-822

51. Anthony T, Murray BW, Sum-Ping JT et al (2011) Evaluating an evidence-based bundle for preventing surgical site infection: a randomized trial. Arch Surg 146(3):263-269

52. Fry DE (2011) Colon preparation and surgical site infection. Am J Surg 202(2):225-232

53. Matsou A, Vrakas G, Doulgerakis M, Hatzimisios K, Zandes N, Saliangas K (2011) Mechanical bowel preparation before elective colorectal surgery: is it necessary? Tech Coloproctol 15(1):59-62

54. Fry DE (2013) The prevention of surgical site infection in elective colon surgery. Scientifica (Cairo). https://doi.org/10.1155/2013/896297

55. Cao F, Li J, Li F (2012) Mechanical bowel preparation for elective colorectal surgery: updated systematic review and meta-analysis. Int J Colorectal Dis 27(6):803-810

56. Zhu QD, Zhang QY, Zeng QQ, Yu ZP, Tao CL, Yang WJ (2010) Efficacy of mechanical bowel prepa- ration with polyethylene glycol in prevention of postoperative complications in elective colorectal surgery: a meta-analysis. Int J Colorectal Dis 25(2):267-275

57. Kim YW, Choi EH, Kim IY, Kwon HJ, Ahn SK (2014) The impact of mechanical bowel preparation in elective colorectal surgery: a propensity score matching analysis. Yonsei Med J 55(5):12731280

58. Kiran RP, Murray AC, Chiuzan C, Estrada D, Forde $\mathrm{K}$ (2015) Combined preoperative mechanical bowel preparation with oral antibiotics significantly reduces surgical site infection, anastomotic leak, and ileus after colorectal surgery. Ann Surg 262(3):416-425

59. Tanner J, Norrie P, Melen K (2011) Preoperative hair removal to reduce surgical site infection. Cochrane Database Syst Rev. https:// doi.org/10.1002/14651858.CD004122.pub4

60. Faruquzzaman HS, Mazumder S (2012) Surgical site infections in relation to the timing of shaving among the gastrointestinal emergency patients through the midline incisions-a randomized controlled clinical trial. J Med Microbiol Diagn 1:111

61. Kramer A, Assadian O, Gruber B, Lademann J (2008) Prävention von postoperativen Wundinfektionen, Teil 1: Präoperative Maßnahmen - Einfluss der Haarentfernung. Hyg Med 33(10):402-407

62. National Institute for Health and Clinical Excellence (NICE) (2008) Surgical site infection: prevention and treatment of surgical site infection (update 2017). Agency for Healthcare Research and Quality (AHRQ), Rockville (URL: https://www.nice.org.uk/guidance/cg74)

63. Toon CD, Sinha S, Davidson BR, Gurusamy KS (2013) Early versus delayed post-operative bathing or showering to prevent wound complications. Cochrane Database Syst Rev. https:// doi.org/10.1002/14651858.CD010075.pub3

64. Hadiati Diah R, Hakimi M, Nurdiati Detty S, Ota E (2014) Skin preparation for preventing infection following caesarean section. Cochrane Database Syst Rev. https://doi.org/10.1002/14651858. CD007462.pub2

65. Webster J, Osborne S (2012) Preoperative bathing or showering with skin antiseptics to prevent surgical site infection. Cochrane Database Syst Rev. https://doi.org/10.1002/14651858. CD004985.pub5

66. Chiang HY, Kamath AS, Pottinger JM et al (2014) Risk factors and outcomes associated with surgical site infections after craniotomy or craniectomy. J Neurosurg 120(2):509-521

67. Shepard J, Ward W, Milstone A et al (2013) Financial impact of surgical site infections on hospitals: the hospital management perspective. JAMA Surg 148(10):907-914

68. Meyer E, Weitzel-Kage D, Sohr D, Gastmeier P (2011) Impact of department volume on surgical site infections following arthroscopy, knee replacement or hip replacement. BMJ Qual Saf 20(12):1069-1074

69. Gastmeier P, Sohr D, Breier A, Behnke M, Geffers $C$ (2011) Prolonged duration of operation: an indicator of complicated surgery or of surgical (mis)management? Infection 39(3):211-215

70. Browne JA, Pietrobon R, Olson SA (2009) Hip fracture outcomes: does surgeon or hospital volume really matter? J Trauma 66(3):809-814

71. Ito M, Sugito M, Kobayashi A, Nishizawa Y, Tsunoda Y, Saito N (2009) Influence of learning curve 
on short-term results after laparoscopic resection for rectal cancer. Surg Endosc 23(2):403-408

72. Arbeitskreis Krankenhaus- und Praxishygiene der AWMF (2010) AWMF-Leitlinien-Register 029/012 - Leitlinien zur Hygiene in Klinik und Praxis: OP-Kleidung und Patientenabdeckung (URL: http://www.awmf.org/leitlinien/detail/ II/029-012.html)

73. Treakle AM, Thom KA, Furuno JP, Strauss SM, Harris AD, Perencevich EN (2009) Bacterial contamination of health care workers' white coats. Am $J$ Infect Control 37(2):101-105

74. Loh W, Ng VV, Holton J (2000) Bacterial flora on the white coats of medical students. J Hosp Infect 45(1):65-68

75. Perry C, Marshall R, Jones E (2001) Bacterial contamination of uniforms. J Hosp Infect 48(3):238-241

76. Zahra M, Yasaman F, Mahboubeh NN, Emran A (2013) Study on bacteria associated with white coats of healthcare workers in two tertiary hospitals, Mashhad, Iran. J Med Bacteriol 2:17-25

77. Munoz-Price LS, Arheart KL, Mills JP et al (2012) Associations between bacterial contamination of health care workers' hands and contamination of white coats and scrubs. Am J Infect Control 40(9):e245-e248

78. Wiener-Well $Y$, Galuty M, Rudensky B, Schlesinger Y, Attias D, Yinnon AM (2011) Nursing and physician attire as possible source of nosocomial infections. Am J Infect Control 39(7):555-559

79. Hubble MJ, Weale AE, Perez JV, Bowker KE, MacGowan AP, Bannister GC (1996) Clothing in laminar-flow operating theatres. J Hosp Infect 32(1):1-7

80. Hamburger M Jr., Green MJ, Hamburger VG (1945) The problem of the dangerous carrier of hemolytic streptococci: II. Spread of infection by individuals with strongly positive nose cultures who expelled large numbers of hemolytic streptococci. J Infect Dis 77(2):96-108

81. Sompolinsky D, Hermann Z, Oeding P, Rippon $J E$ (1957) A series of postoperative infections. J Infect Dis 100(1):1-11

82. Mclntyre DM (1968) An epidemic of Streptococcus pyogenes puerperal and postoperative sepsis with an unusual carrier site--the anus. Am J Obstet Gynecol 101(3):308-314

83. Schaffner W, Lefkowitz LB Jr., Goodman JS, Koenig MG (1969) Hospital outbreak of infections with group a streptococci traced to an asymptomatic anal carrier. N Engl J Med 280(22):1224-1225

84. Dineen P, Drusin L (1973) Epidemics of postoperative wound infections associated with hair carriers. Lancet 2(7839):1157-1159

85. Berkelman RL, Martin D, Graham DR et al (1982) Streptococcal wound infections caused by a vaginal carrier. JAMA 247(19):2680-2682

86. Mastro TD, Farley TA, Elliott JA et al (1990) An outbreak of surgical-wound infections due to group A streptococcus carried on the scalp. N Engl J Med 323(14):968-972

87. Kolmos HJ, Svendsen RN, Nielsen SV (1997) The surgical team as a source of postoperative wound infections caused by streptococcus pyogenes. J Hosp Infect 35(3):207-214

88. Centers for Disease Control and Prevention (1999) Nosocomial group A streptococcal infections associated with asymptomatic health-care workers - Maryland and California, 1997. MMWR Morb Mortal Wkly Rep 48(8):163-166
89. Wenger PN, Brown JM, McNeil MM, Jarvis WR (1998) Nocardia farcinica sternotomy site infections in patients following open heart surgery. J Infect Dis 178(5):1539-1543

90. Assadian O, Kramer A (2011) Durchführung der präoperativen Hautantiseptik im Rahmen der Prävention postoperativer Wundinfektionen und Auswahl der infrage kommenden Hautantiseptika. Hyg Med 36(5):186-190

91. Dumville JC, McFarlane E, Edwards P, Lipp A, Holmes A (2013) Preoperative skin antiseptics for preventing surgical wound infections after clean surgery. Cochrane Database Syst Rev. https:// doi.org/10.1002/14651858.CD003949.pub3

92. Reichel M, Heisig P, Kohlmann T, Kampf G (2009) Alcohols for skin antisepsis at clinically relevant skin sites. Antimicrob Agents Chemother 53(11):4778-4782

93. Maiwald M, Chan ES (2012) The forgotten role of alcohol: a systematic review and meta-analysis of the clinical efficacy and perceived role of chlorhexidine in skin antisepsis. PLoS ONE 7(9):e44277

94. Lee I, Agarwal RK, Lee BY, Fishman NO, Umscheid CA (2010) Systematic review and cost analysis comparing use of chlorhexidine with use of iodine for preoperative skin antisepsis to prevent surgical site infection. Infect Control Hosp Epidemiol 31(12):1219-1229

95. Huang EY, Chen C, Abdullah F et al (2011) Strategies for the prevention of central venous catheter infections: an American Pediatric Surgical Association Outcomes and Clinical Trials Committee systematic review. J Pediatr Surg 46(10):2000-2011

96. Edmiston CE Jr., Seabrook GR, Johnson CP, Paulson DS, Beausoleil CM (2007) Comparative of a new and innovative $2 \%$ chlorhexidine gluconate-impregnated cloth with $4 \%$ chlorhexidine gluconate as topical antiseptic for preparation of the skin prior to surgery. Am J Infect Control 35(2):89-96

97. Ulmer M, Lademann J, Patzelt A et al (2014) New strategies for preoperative skin antisepsis. Skin Pharmacol Physiol 27(6):283-292

98. Cordtz T, Schouenborg L, Laursen K et al (1989) The effect of incisional plastic drapes and redisinfection of operation site on wound infection following caesarean section. J Hosp Infect 13(3):267-272

99. Gaspard F, Brassard P, Alam T et al (2013) Impact of an antimicrobial dressing in reducing surgical site infections in cardiac surgery patients. Wounds 25(7):178-185

100. Mueller SW, Krebsbach LE (2008) Impact of an antimicrobial-impregnated gauze dressing on surgical site infections including methicillinresistant staphylococcus aureus infections. Am J Infect Control 36(9):651-655

101. Müller G, Kramer A (2005) Effect of selected wound antiseptics on adult articular cartilage (bovine sesamoid bone) in the presence of Escherichia coli and Staphylococcus aureus. J Orthop Res 23(1):127-133

102. Müller R (2008) Antiseptika bei HNO-Erkrankungen. Laryngorhinootologie 87(01):52-60

103. Speaker MG, Menikoff JA (1991) Prophylaxis of endophthalmitis with topical povidone-iodine. Ophthalmology 98(12):1769-1775

104. Hansmann F, Kramer A, Ohgke H, Strobel H, Müller M, Geerling G (2004) Polyhexamethylbiguanid (PHMB) zur präoperativen Antisepsis bei
Kataraktoperation. Ophthalmologe 101(4):377383

105. von Eckardstein AS, Lim CH, Dohmen PM et al (2011) A randomized trial of a skin sealant to reduce the risk of incision contamination in cardiac surgery. Ann Thorac Surg 92(2):632-637

106. Vierhout BP, Ott A, Reijnen MMPJ, Oskam J, Van Den Dungen JJAM, Zeebregts CJ (2014) Cyanoacrylate skin microsealant for preventing surgical site infection after vascular surgery: a discontinued randomized clinical trial. Surg Infect (Larchmt) 15(4):425-430

107. Hanedan MO, Unal EU, Aksoyek A et al (2014) Comparison of two different skin preparation strategies for open cardiac surgery. J Infect Dev Ctries 8(7):885-890

108. Dromzee E, Tribot-Laspiere Q, Bachy M, Zakine S, Mary P, Vialle R (2012) Efficacy of integuseal for surgical skin preparation in children and adolescents undergoing scoliosis correction. Spine 37(21):E1331-E1335

109. Thomas E, Nugent E, McMeekin D (2013) Effectiveness of cyanoacrylate microbial sealant (CMS) in the reduction of surgical site infection in gynecologic oncology procedures: a singlecenter randomized study: interim analysis. Gynecol Oncol 130(1):e58-e59

110. Doorly M, Choi J, Floyd A, Senagore A (2015) Microbial sealants do not decrease surgical site infection for clean-contaminated colorectal procedures. Tech Coloproctol 19(5):281-285

111. Iyer A, Gilfillan I, Thakur S, Sharma S (2011) Reduction of surgical site infection using a microbial sealant: a randomized trial. J Thorac Cardiovasc Surg 142(2):438-442

112. Pabon DF, Yost MJ, Melendez GC et al (2010) Novel bacterial immobilization compound effectively decreases bacterial counts in healthy volunteers. Am Surg 76(1):15-19

113. Lipp A, Phillips C, Harris P, Dowie I (2013) Cyanoacrylate microbial sealants for skin preparation prior to surgery. Cochrane Database Syst Rev. https://doi.org/10.1002/14651858.CD008062. pub2

114. Whyte W, Hamblen DL, Kelly IG, Hambraeus A Laurell G (1990) An investigation of occlusive polyester surgical clothing. J Hosp Infect 15(4):363-374

115. DIN EN 13795-1 Operationskleidung und -abdecktücher - Anforderungen und Prüfverfahren - Teil 1: Operationsabdecktücher und -mäntel; Deutsche und Englische Fassung prEN 137951:2017.

116. Ortiz H, Armendariz P, Kreisler E et al (2012) Influence of rescrubbing before laparotomy closure on abdominal wound infection after colorectal cancer surgery: results of a multicenter randomized clinical trial. Arch Surg 147(7):614-620

117. Ortiz H, Kreisler E, Armendariz P et al (2011) Influence of two policies of closure of the laparotomy wound on the incidence of incisional surgical site infection in colorectal cancer surgery. Results of a randomised trial. Colorectal Dis 13:1

118. Whyte W (1988) The role of clothing and drapes in the operating room. J Hosp Infect 11(Suppl C):2-17

119. Cherif C, Günther $E$, Jatzwauck $L$, Mecheels $S$ (Hrsg) (2009) Evaluierung von OP-Textilien. Ergebnisse einer Untersuchung nach hygienischen, ökonomischen und ökologischen Gesichtspunkten. Technische Universität Dresden. Institut für Textil- und Bekleidungstechnik, Dresden 
120. Verkkala K, Eklund A, Ojajärvi J, Tiittanen L, Hoborn J, Mäkelä P (1998) The conventionally ventilated operating theatre and air contamination control during cardiac surgery - bacteriological and particulate matter control garment options for low level contamination. Eur J Cardiothorac Surg 14(2):206-210

121. Werner HP, Hoborn J, Schön K, Petri E (1991) Influence of drape permeability on wound contamination during mastectomy. Eur J Surg 157(6):379-383

122. Moylan JA, Kennedy BV (1980) The importance of gown and drape barriers in the prevention of wound infection. Surg Gynecol Obstet 151(4):465-470

123. Webster J, Alghamdi A (2013) Use of plastic adhesive drapes during surgery for preventing surgical site infection. Cochrane Database Syst Rev. https://doi.org/10.1002/14651858 CD006353.pub4

124. Casey AL, Karpanen TJ, Nightingale P, Conway BR, Elliott TS (2015) Antimicrobial activity and skin permeation of iodine present in an iodineimpregnated surgical incise drape. J Antimicrob Chemother 70(8):2255-2260

125. Kramer A, Assadian O, Lademann J (2010) Prevention of postoperative wound infections by covering the surgical field with iodineimpregnated incision drape (loban 2). GMS Krankenhhyg Interdiszip 5(2):Doc8. https:// doi.org/10.3205/dgkh000151

126. Bejko J, Tarzia V, Carrozzini M et al (2015) Comparison of efficacy and cost of iodine impregnated drape vs. standard drape in cardiac surgery: study in 5100 patients. J Cardiovasc Transl Res 8(7):431-437

127. Hübner N, Kampf G, Löffler H, Kramer A (2006) Effect of a 1 minute hand wash on the bactericidal efficacy of standard alcohols for surgical hand disinfection and on skin hydration. Int J Hyg Environ Health 208:285-291

128. Kramer A, Hübner $\mathrm{N}$, Below $\mathrm{H}$, Heidecke CD, Assadian $O$ (2008) Improving adherence to surgical hand preparation. J Hosp Infect 70(Suppl 1):35-43

129. Kampf G, Kramer A, Suchomel M (2017) Lack of sustained efficacy for alcohol-based surgical hand rubs containing 'residual active ingredients' according to EN 12791. J Hosp Infect 95(2):163-168

130. Kommission für Krankenhaushygiene und Infektionsprävention (KRINKO) (2016) Händehygiene in Einrichtungen des Gesundheitswesens. Bundesgesundheitsblatt 59(9):1189-1220

131. Misteli H, Weber WP, Reck S et al (2009) Surgical glove perforation and the risk of surgical site infection. Arch Surg 144(6):553-558

132. Gerberding JL, Littell C, Tarkington A, Brown A Schecter WP (1990) Risk of exposure of surgica personnel to patients' blood during surgery at San Francisco General Hospital. N Engl J Med 322(25):1788-1793

133. Thomas S, Agarwal M, Mehta G (2001) Intraoperative glove perforation--single versus double gloving in protection against skin contamination. Postgrad Med J 77(909):458-460

134. Goyal S, Singh M (2014) Incidence of perforation of single and double gloves during surgery. CIBTech J Surg 3(3):21-24

135. Daeschlein G, Kramer A, Arnold A, Ladwig A Seabrook GR, Edmiston CE Jr (2011) Evaluation of an innovative antimicrobial surgical glove technology to reduce the risk of microbial pas- sage following intraoperative perforation. Am J Infect Control 39(2):98-103

136. Pitten F, Müller P, Heeg P, Kramer A (1998) Untersuchungen zur wiederholten Desinfizierbarkeit von Einweghandschuhen während des Tragens. Zentralbl Hyg Umweltmed 201(6):555-562

137. Assadian O, Kramer A, Ouriel K et al (2014) Suppression of surgeons' bacterial hand flora during surgical procedures with a new antimicrobial surgical glove. Surg Infect (Larchmt) 15(1):43-49

138. Harnoss JC, Partecke LI, Heidecke CD, Hubner NO, Kramer A, Assadian O (2010) Concentration of bacteria passing through puncture holes in surgical gloves. Am J Infect Control 38(2):154158

139. Partecke LI, Goerdt AM, Langner I et al (2009) Incidence of microperforation for surgical gloves depends on duration of wear. Infect Control Hosp Epidemiol 30(5):409-414

140. Hübner NO, Goerdt AM, Stanislawski N et al (2010) Bacterial migration through punctured surgical gloves under real surgical conditions. BMC Infect Dis 10:192

141. Mischke C, Verbeek JH, Saarto A, Lavoie MC, Pahwa M, ljaz S (2014) Gloves, extra gloves or special types of gloves for preventing percutaneous exposure injuries in healthcare personnel. Cochrane Database Syst Rev. https:// doi.org/10.1002/14651858.CD009573.pub2

142. Korniewicz D, El-Masri M (2012) Exploring the benefits of double gloving during surgery. AORN J 95(3):328-336

143. Tanner J, Parkinson H (2006) Double gloving to reduce surgical cross-infection. Cochrane Database Syst Rev. https:// doi.org/10.1002/14651858.cd003087

144. Kampf G, Ostermeyer C (2009) A 1-minute hand wash does not impair the efficacy of a propanol-based hand rub in two consecutive surgical hand disinfection procedures. Eur J Clin Microbiol Infect Dis 28(11):1357-1362

145. Kampf G, Ostermeyer C, Kohlmann T (2008) Bacterial population kinetics on hands during 2 consecutive surgical hand disinfection procedures. Am J Infect Control 36(5):369-374

146. Hübner N, Rubbert K, Pohrt U, Heidecke $C$, Partecke L, Kramer A (2016) Einsatz wiederaufbereitbarer textiler Unterziehhandschuhe für medizinische Tätigkeiten: eine Machbarkeitsstudie. Zentralbl Chir 141(1):62-67

147. Parry MF, Grant B, Yukna M et al (2001) Candida osteomyelitis and diskitis after spinal surgery: an outbreak that implicates artificial nail use. Clin Infect Dis 32(3):352-357

148. Passaro DJ, Waring L, Armstrong R et al (1997) Postoperative serratia marcescens wound infections traced to an out-of-hospital source. J Infect Dis 175(4):992-995

149. Porteous J (2002) Artificial nails... very real risks. Can Oper Room Nurs J 20(3):16-17, 20-11

150. Nicolai P, Aldam CH, Allen PW (1997) Increased awareness of glove perforation in major joint replacement. A prospective, randomised study of regent biogel reveal gloves. J Bone Joint Surg Br 79(3):371-373

151. TRBA 250 (2016) Biologische Arbeitsstoffe im Gesundheitswesen und in der Wohlfahrtspflege. GMBI (42):838

152. McHugh SM, Hill AD, Humphreys H (2011) Intraoperative technique as a factor in the prevention of surgical site infection. J Hosp Infect 78(1):1-4

153. Hansis ML, Arens S, Baumann N et al (1999) Die chirurgische Verfahrenswahl kompensiert ein erhöhtes Infektionsrisiko Nationale prospektive Multizenterstudie bei 1813 Patienten zur Frage der infektprädisponierenden Faktoren bei knöchernen Eingriffen am Unterschenkel. Aktuelle Traumatol 29:144-151

154. Linni K, Ugurluoglu A, Hitzl W, Aspalter M, Hölzenbein T (2014) Bioabsorbable stent implantation vs. common femoral artery endarterectomy: early results of a randomized trial. J Endovasc Ther 21(4):493-502

155. Roopram AD, Lind MY, Van Brussel JP et al (2013) Endovenous laser ablation versus conventional surgery in the treatment of small saphenous vein incompetence. J Vasc Surg 1(4):357-363

156. Kaafarani HM, Kaufman D, Reda D, Itani KM (2010) Predictors of surgical site infection in laparoscopic and open ventral incisional herniorrhaphy. J Surg Res 163(2):229-234

157. Brandt C, Hott U, Sohr D, Daschner F, Gastmeier $\mathrm{P}$, Rüden $\mathrm{H}$ (2008) Operating room ventilation with laminar airflow shows no protective effect on the surgical site infection rate in orthopedic and abdominal surgery. Ann Surg 248(5):695700

158. Kaoutzanis C, Leichtle SW, Mouawad NJ, Welch KB, Lampman RM, Cleary RK (2013) Postoperative surgical site infections after ventral/incisional hernia repair: a comparison of open and laparoscopic outcomes. Surg Endosc 27(6):2221-2230

159. Boni L, Benevento A, Rovera F et al (2006) Infective complications in laparoscopic surgery. Surg Infect (Larchmt) 7(Suppl 2):S109-S111

160. Perugini RA, Callery MP (2001) Complications of laparoscopic surgery. In: Holzheimer RG, John A, Mannick JA (Hrsg) Surgical treatment. Evidencebased and problem-oriented. Zuckschwerdt, München

161. Sauerland S, Lefering R, Neugebauer EA (2004) Laparoscopic versus open surgery for suspected appendicitis. Cochrane Database Syst Rev. https://doi.org/10.1002/14651858.CD001546. pub3

162. Aziz O, Athanasiou T, Tekkis PP et al (2006) Laparoscopic versus open appendectomy in children: a meta-analysis. Ann Surg 243(1):17-27

163. Ingraham AM, Cohen ME, Bilimoria KY, Pritts TA, Ko CY, Esposito TJ (2010) Comparison of outcomes after laparoscopic versus open appendectomy for acute appendicitis at 222 ACS NSQIP hospitals. Surgery 148(4):625-637

164. Markides G, Subar D, Riyad K (2010) Laparoscopic versus open appendectomy in adults with complicated appendicitis: systematic review and meta-analysis. World J Surg 34(9):2026-2040

165. Siddiqui S, Heidel RE, Angel CA, Kennedy AP Jr. (2012) Pyloromyotomy: randomized control trial of laparoscopic vs open technique. J Pediatr Surg 47(1):93-98

166. Mohan HM, McDermott $S$, Fenelon L et al (2012) Plastic wound retractors as bacteriological barriers in gastrointestinal surgery: a prospective multi-institutional trial. J Hosp Infect 81(2):109-113

167. Cheng KP, Roslani AC, Sehha N et al (2012) ALEXIS O-Ring wound retractor vs conventional wound protection for the prevention of surgical site infections in colorectal resections1. Colorectal Dis 14(6):e346-e351

168. Reid K, Pockney P, Draganic B, Smith SR (2010) Barrier wound protection decreases surgical site infection in open elective colorectal surgery: a randomized clinical trial. Dis Colon Rectum 53(10):1374-1380 
169. Horiuchi T, Tanishima H, Tamagawa K et al (2007) Randomized, controlled investigation of the anti-infective properties of the Alexis retractor/ protector of incision sites. J Trauma Acute Care Surg 62(1):212-215

170. Nystrom PO, Brote L (1980) Effects of a plastic wound drape on contamination with enterobacteria and on infection after appendicectomy. Acta Chir Scand 146(1):65-70

171. Edwards JP, Ho AL, Tee MC, Dixon E, Ball CG (2012) Wound protectors reduce surgical site infection: a meta-analysis of randomized controlled trials. Ann Surg 256(1):53-59

172. Pinkney TD, Calvert M, Bartlett DC et al (2013) Impact of wound edge protection devices on surgical site infection after laparotomy: multicentre randomised controlled trial (ROSSINI Trial). BMJ 347:f4305

173. Nystrom PO, Broome A, Hojer H, Ling L (1984) A controlled trial of a plastic wound ring drape to prevent contamination and infection in colorectal surgery. Dis Colon Rectum 27(7):451-453

174. Psaila JV, Wheeler MH, Crosby DL (1977) The role of plastic wound drapes in the prevention of wound infection following abdominal surgery. Br J Surg 64(10):729-732

175. Gheorghe A, Calvert M, Pinkney TD et al (2012) Systematic review of the clinical effectiveness of wound-edge protection devices in reducing surgical site infection in patients undergoing open abdominal surgery. Ann Surg 255(6):1017-1029

176. Khan S, Khan S, Chawla T, Murtaza G (2014) Harmonic scalpel versus electrocautery dissection in modified radical mastectomy: a randomized controlled trial. Ann Surg Oncol 21(3):808-814

177. Rongetti RL, Oliveira e Castro Pde T, Vieira RA Serrano SV, Mengatto MF, Fregnani JH (2014) Surgical site infection: an observer-blind, randomized trial comparing electrocautery and conventional scalpel. Int J Surg 12(7):681-687

178. Anlar B, Karaman N, Dogan L, Ozaslan C, Atalay C, Altinok M (2013) The effect of harmonic scalpel, electrocautery, and scalpel use on early wound complications after modified radical mastectomy. Eur Surg 45(6):286-290

179. Hasselgren PO, Hagberg E, Malmer H, Saljo A, Seeman T (1984) One instead of two knives for surgical incision. Does it increase the risk of postoperative wound infection? Arch Surg 119(8):917-920

180. Tejwani NC, Immerman I (2008) Myths and legends in orthopaedic practice: are we all guilty? Clin Orthop Relat Res 466(11):2861-2872

181. Fitzgerald RH Jr., Washington JA 2nd (1975) Contamination of the operative wound. Orthop Clin North Am 6(4):1105-1114

182. Hemker T (1982) Luftkeimzahlpegel während Operationen. Langenbecks Arch Chir 359(2):93-99

183. Bible JE, O'Neill KR, Crosby CG, Schoenecker JG, McGirt MJ, Devin CJ (2013) Implant contamination during spine surgery. Spine J 13(6):637-640

184. Kim BD, Hsu WK, De Oliveira GS Jr., Saha S, Kim JY (2014) Operative duration as an independent risk factor for postoperative complications in single-level lumbar fusion: an analysis of 4588 surgical cases. Spine 39(6):510-520

185. Jeong SJ, Ann HW, Kim JK et al (2013) Incidence and risk factors for surgical site infection after gastric surgery: a multicenter prospective cohort study. Infect Chemother 45(4):422-430

186. Matar WY, Jafari SM, Restrepo C, Austin M, Purtill JJ, Parvizi J (2010) Preventing infection in total joint arthroplasty. J Bone Joint Surg Am 92(Suppl 2):36-46

187. Ridgeway S, Wilson J, Charlet A, Kafatos G, Pearson A, Coello R (2005) Infection of the surgical site after arthroplasty of the hip. J Bone Joint Surg Br 87(6):844-850

188. Ku CH, Ku SL, Yin JC, Lee AJ (2005) Risk factors for sternal and leg surgical site infections after cardiac surgery in Taiwan. Am J Epidemiol 161(7):661-671

189. Guggenbichler JP, Assadian O, Boeswald M, Kramer A (2011) Incidence and clinical implication of nosocomial infections associated with implantable biomaterials - catheters, ventilatorassociated pneumonia, urinary tract infections. GMS Krankenhhyg Interdiszip 6(1):Doc18

190. Gómez-Alonso A, García-Criado FJ, ParreñoManchado FC et al (2007) Study of the efficacy of coated VICRYL plus ${ }^{\oplus}$ antibacterial suture (coated polyglactin 910 suture with triclosan) in two animal models of general surgery. J Infect 54(1):82-88

191. Chu CC, Williams DF (1984) Effects of physical configuration and chemical structure of suture materials on bacterial adhesion: a possible link to wound infection. Am J Surg 147(2):197-204

192. Arslan N, Terzi C, Atasoy G et al (2014) Effect of triclosan coated sutures on surgical site infection rate in pilonidal sinus disease: single-blinded randomized trial. Dis Colon Rectum 57(5):e255

193. Okada N, Nakamura T, Ambo Y et al (2014) Triclosan-coated abdominal closure sutures reduce the incidence of surgical site infections after pancreaticoduodenectomy. Surg Infect (Larchmt) 15(3):305-309

194. Diener MK, Knebel P, Kieser M et al (2014) Effectiveness of triclosan-coated PDS plus versus uncoated PDS II sutures for prevention of surgical site infection after abdominal wall closure: the randomised controlled PROUD trial. Lancet 384(9938):142-152

195. Thimour-Bergstrom L, Roman-Emanuel C, Schersten $\mathrm{H}$, Friberg $\mathrm{O}$, Gudbjartsson T, Jeppsson A (2013) Triclosan-coated sutures reduce surgical site infection after open vein harvesting in coronary artery bypass grafting patients: a randomized controlled trial. Eur J Cardiothorac Surg 44(5):931-938

196. Justinger C, Slotta JE, Ningel S, Graber S, Kollmar O, Schilling MK (2013) Surgical-site infection after abdominal wall closure with triclosanimpregnated polydioxanone sutures: results of a randomized clinical pathway facilitated trial (NCT00998907). Surgery 154(3):589-595

197. Mattavelli I, Nespoli L, Alfieri S et al (2013) Effect of Triclosan-coated suture on surgical site infection after colorectal surgery: final results of a multicenter, prospective, randomized trial. Surg Infect (Larchmt) 14(2):A-9/013

198. Turtiainen J, Saimanen El, Makinen KT et al (2012) Effect of triclosan-coated sutures on the incidence of surgical wound infection after lower limb revascularization surgery: a randomized controlled trial. World J Surg 36(10):2528-2534

199. Huszar O, Baracs J, Toth M et al (2012) Comparison of wound infection rates after colon and rectal surgeries using triclosan-coated or bare sutures -- a multi-center, randomized clinical study. Magy Seb 65(3):83-91

200. Williams N, Sweetland H, Goyal S, Ivins N, Leaper DJ (2011) Randomized trial of antimicrobialcoated sutures to prevent surgical site infection after breast cancer surgery. Surg Infect (Larchmt) 12(6):469-474

201. Galal I, El-Hindawy K (2011) Impact of using triclosan-antibacterial sutures on incidence of surgical site infection. Am J Surg 202(2):133-138

202. Berríos-Torres SI, Umscheid CA, Bratzler DW et al (2017) Centers for disease control and prevention guideline for the prevention of surgical site infection, 2017. JAMA Surg 152(8):784-791. https://doi.org/10.1001/jamasurg.2017.0904

203. Härle A (1981) Wunddrainage. Hyg Med 6(4):127-113

204. Khan S, Bawa T, Tanveer D, Raffique S (2014) Modified radical mastectomy using 1 vs 2 drains: a randomized controlled trial. Ann Surg Oncol 21(2 Suppl):68-68

205. Akinyoola AL, Odunsi A, Yusu MB (2012) Use of wound drains following open reduction and internal fixation of femoral shaft fractures. J Wound Care 21(6):279-280, 282-274

206. Ali SA, Tahir SM, Soomoro AG, Siddiqui AJ, Memon AS (2010) Open cholecystectomy without intraperitoneal drainage. J Ayub Med Coll Abbottabad 22(2):29-31

207. Kaya E, Paksoy E, Ozturk E, Sigirli D, Bilgel H (2010) Subcutaneous closed-suction drainage does not affect surgical site infection rate following elective abdominal operations: a prospective randomized clinical trial. Acta Chir Belg 110(4):457-462

208. Baier PK, Gluck NC, Baumgartner U, Adam U, Fischer A, Hopt UT (2010) Subcutaneous Redon drains do not reduce the incidence of surgical site infections after laparotomy. A randomized controlled trial on 200 patients. Int J Colorectal Dis 25(5):639-643

209. de Jesus EC, Karliczek A, Matos D, Castro AA, Atallah ÁN (2004) Prophylactic anastomotic drainage for colorectal surgery. Cochrane Database Syst Rev. https://doi.org/10.1002/14651858. CD002100.pub2

210. von Roth P, Perka C, Dirschedl K et al (2012) Use of Redon drains in primary total hip arthroplasty has no clinically relevant benefits. Orthopedics 35(11):e1592-e1595

211. Zhou XD, Li J, Xiong Y, Jiang LF, Li WJ, Wu LD (2013) Do we really need closed-suction drainage in total hip arthroplasty? A meta-analysis. Int Orthop 37(11):2109-2118

212. Tang R, Chen HH, Wang YL et al (2001) Risk factors for surgical site infection after elective resection of the colon and rectum: a single-center prospective study of 2,809 consecutive patients. Ann Surg 234(2):181-189

213. Imada S, Noura S, Ohue M et al (2013) Efficacy of subcutaneous penrose drains for surgical site infections in colorectal surgery. World J Gastrointest Surg 5(4):110-114

214. Rao SB, Vasquez G, Harrop J et al (2011) Risk factors for surgical site infections following spinal fusion procedures: a case-control study. Clin Infect Dis 53(7):686-692

215. Millbourn D, Cengiz Y, Israelsson LA (2009) Effect of stitch length on wound complications after closure of midline incisions: a randomized controlled trial. Arch Surg 144(11):1056-1059

216. Deerenberg EB, Harlaar JJ, Steyerberg EW et al (2015) Small bites versus large bites for closure of abdominal midline incisions (STITCH): a double-blind, multicentre, randomised controlled trial. Lancet 386(10000):1254-1260 
217. Israelsson LA, Millbourn D (2012) Closing midline abdominal incisions. Langenbecks Arch Surg 397(8):1201-1207

218. Gurusamy KS, Toon CD, Allen VB, Davidson BR (2014) Continuous versus interrupted skin sutures for non-obstetric surgery. Cochrane Database Syst Rev. https:// doi.org/10.1002/14651858.CD010365.pub2

219. Biancari F, Tiozzo V (2010) Staples versus sutures for closing leg wounds after vein graft harvesting for coronary artery bypass surgery. Cochrane Database Syst Rev. https:// doi.org/10.1002/14651858.CD008057.pub2

220. Dancer SJ (2009) The role of environmental cleaning in the control of hospital-acquired infection. J Hosp Infect 73(4):378-385

221. Yezli S, Barbut F, Otter JA (2014) Surface contamination in operating rooms: a risk for transmission of pathogens? Surg Infect (Larchmt) 15(6):694-699

222. Knochen $\mathrm{H}$, Hubner NO, Below $\mathrm{H}$ et al (2010) Influence of floor disinfection on microbial and particulate burden measured under low turbulance air flow in ophthalmological operation theatres. Klin Monbl Augenheilkd 227(11):871878

223. Liguori G, Spagnoli G, Agozzino E et al (2005) Biological risk in the operating room: microbiological monitoring of the environment and analysis of the associated variables. Ann lg 17(5):385-400

224. Javed I, Hafeez R, Zubair M, Anwar M, Tayyib M, Husnain S (2008) Microbiological surveillance of operation theatres and ICUs of a tertiary care hospital, Lahore. Biomedica 24:99-102

225. Gebremariam T, Declaro M (2014) Operating theaters as a source of nosocomial infection: a systematic review. Saudi J Health Sci 3(1):5-8

226. Suzuki $A$, Namba $Y$, Matsuura $M$, Horisawa $A$ (1984) Bacterial contamination of floors and other surfaces in operating rooms: a five-year survey. Epidemiol Infect 93(03):559-566

227. Alexander JW, Van Sweringen $\mathrm{H}$, VanOss $\mathrm{K}$, Hooker EA, Edwards MJ (2013) Surveillance of bacterial colonization in operating rooms. Surg Infect (Larchmt) 14(4):345-351

228. Fukada T, Iwakiri H, Ozaki M (2008) Anaesthetists' role in computer keyboard contamination in an operating room. J Hosp Infect 70(2):148153

229. Griffith C, Cooper R, Gilmore J, Davies C, Lewis M (2000) An evaluation of hospital cleaning regimes and standards. J Hosp Infect 45(1):19-28

230. Munoz-Price LS, Lubarsky DA, Arheart KL et al (2013) Interactions between anesthesiologists and the environment while providing anesthesia care in the operating room. Am J Infect Control 41(10):922-924

231. National Health Service Estates (NHS) (2001) National standards of cleanliness for the NHS

232. Association of periOperative Registered Nurses (AORN) (2002) Recommended practices for environmental cleaning in the surgical practice setting. Aorn J 76(6):1071-1076

233. Kommission für Krankenhaushygiene und Infektionsprävention (KRINKO) (2004) Anforderungen an die Hygiene bei der Reinigung und Desinfektion von Flächen. Bundesgesundheitsblatt 47(1):51-61

234. Kommission für Krankenhaushygiene und Infektionsprävention (KRINKO) (2012) Anforderungen an die Hygiene bei der Aufbereitung von Medizinprodukten. Bundesgesundheitsblatt 55(10):1244-1310

235. Altemeier WA, Culbertson WR, Hummel RP (1968) Surgical considerations of endogenous infections--sources, types, and methods of control. Surg Clin North Am 48(1):227-240

236. Edwards LD (1976) The epidemiology of 2056 remote site infections and 1966 surgical wound infections occurring in 1865 patients: a four year study of 40,923 operations at Rush-Presbyterian-St. Luke's Hospital, Chicago. Ann Surg 184(6):758-766

237. Noble W (2004) The skin microflora and microbial skin disease. Cambridge University Press, Cambridge

238. Faraday N, Rock P, Lin EE et al (2013) Past history of skin infection and risk of surgical site infection after elective surgery. Ann Surg 257(1):150-154

239. Berthelot P, Grattard F, Cazorla C et al (2010) Is nasal carriage of staphylococcus aureus the main acquisition pathway for surgical-site infection in orthopaedic surgery? Eur J Clin Microbiol Infect Dis 29(4):373-382

240. Rao N, Cannella BA, Crossett LS, Yates AJ Jr, McGough lii RL, Hamilton CW (2011) Preoperative screening/decolonization for staphylococcus aureus to prevent orthopedic surgical site infection: prospective cohort study with 2-year follow-up. J Arthroplasty 26(8):1501-1507

241. Levy PY, Ollivier M, Drancourt M, Raoult D, Argenson JN (2013) Relation between nasal carriage of staphylococcus aureus and surgical site infection in orthopedic surgery: the role of nasal contamination. A systematic literature review and meta-analysis. Orthop Traumatol Surg Res 99(6):645-651

242. Hübner N, Wander K, Ryll S, Lindstedt G, Kramer A (2009) Antibiotikafreie Sanierung von MRSA-positivem Personal. GMS Krankenhhyg Interdiszip 4(2):1-4

243. Lamplot JD, Luther G, Mawdsley EL, Luu HH, Manning D (2015) Modified protocol decreases surgical site infections after total knee arthroplasty. J Knee Surg 28(5):395-403

244. Bebko SP, Green DM, Awad SS (2015) Effect of a preoperative decontamination protocol on surgical site infections in patients undergoing elective orthopedic surgery with hardware implantation. JAMA Surg 150(5):390-395

245. Phillips M, Rosenberg A, Shopsin B et al (2014) Preventing surgical site infections: a randomized, open-label trial of nasal mupirocin ointment and nasal povidone-iodine solution. Infect Control Hosp Epidemiol 35(07):826-832

246. Johnson AJ, Kapadia BH, Daley JA, Molina CB, Mont MA (2013) Chlorhexidine reduces infections in knee arthroplasty. J Knee Surg 26(3):213-218

247. Patel JB, Gorwitz RJ, Jernigan JA (2009) Mupirocin resistance. Clin Infect Dis 49(6):935-941

248. Lee AS, Macedo-Vinas M, François P et al (2011) Impact of combined low-level mupirocin and genotypic chlorhexidine resistance on persistent methicillin-resistant staphylococcus aureus carriage after decolonization therapy: a Case-Control Study. Clin Infect Dis 52(12):1422-1430

249. Bathoorn E, Hetem DJ, Alphenaar J, Kusters JG, Bonten MJ (2012) Emergence of high-level mupirocin resistance in coagulase-negative staphylococci associated with increased short-term mupirocin use. J Clin Microbiol 50(9):2947-2950

250. Horner C, Mawer D, Wilcox M (2012) Reduced susceptibility to chlorhexidine in staphylococci: is it increasing and does it matter? J Antimicrob Chemother 67(11):2547-2559

251. European Centre for Disease Prevention and Control (ECDC) (2013) Systematic review and evidence-based guidance on perioperative antibiotic prophylaxis. (Technical Report). ECDC, Stockholm (URL: https://ecdc.europa.eu/sites/ portal/files/media/en/publications/Publications/ Perioperative\%20antibiotic\%20prophylaxis\%20 -\%20June\%202013.pdf)

252. Ullah B, Khan SA, Ahmed S, Pasha T (2013) Efficacy of preoperative single dose antibiotic in patients undergoing mesh repair for inguinal hernia. J Ayub Med Coll Abbottabad 25(1-2):103-105

253. Mazaki T, Mado K, Masuda H, Shiono M, Tochikura N, Kaburagi M (2014) A randomized trial of antibiotic prophylaxis for the prevention of surgical site infection after open mesh-plug hernia repair. Am J Surg 207(4):476-484

254. Smith SC, Heal CF, Buttner PG (2014) Prevention of surgical site infection in lower limb skin lesion excisions with single dose oral antibiotic prophylaxis: a prospective randomised placebo-controlled double-blind trial. BMJ Open 4(7):e5270

255. Gulluoglu BM, Guler SA, Ugurlu MU, Culha $\mathrm{G}$ (2013) Efficacy of prophylactic antibiotic administration for breast cancer surgery in overweight or obese patients: a randomized controlled trial. Ann Surg 257(1):37-43

256. Sinha LM, Khan AH, Khan A, Yunus A (2012) Should the duration of antibiotics prophylaxis be prolonged in diabetes patients with isolated coronary artery bypass grafting? Pak J Med Health Sci 6(2):495-498

257. Jan N, Abbas Z, Ahmed MN, Tandon VR, Imram M, Parveen S, Bhat GH (2012) Prospective randomized open labeled study comparing prophylactic efficacy of parenteral single dose cefuroxime vs ampicillin-sulbactam in patients undergoing elective cholecystectomy. JK Sci 14(2):77

258. Iribarren O, Araujo M (2006) Effect of antimicrobial prophylaxis on the incidence of infections in clean surgical wounds in hospitals undergoing renovation. Infect Control Hosp Epidemiol 27(12):1372-1376

259. Petignat C, Francioli P, Harbarth S et al (2008) Cefuroxime prophylaxis is effective in noninstrumented spine surgery: a double-blind, placebocontrolled study. Spine 33(18):1919-1924

260. Kato D, Maezawa K, Yonezawa l et al (2006) Randomized prospective study on prophylactic antibiotics in clean orthopedic surgery in one ward for 1 year. J Orthop Sci 11(1):20-27

261. Gillespie WJ, Walenkamp GH (2010) Antibiotic prophylaxis for surgery for proximal femoral and other closed long bone fractures. Cochrane Database Syst Rev. https:// doi.org/10.1002/14651858.CD000244.pub2

262. Jones DJ, Bunn F, Bell-Syer SV (2014) Prophylactic antibiotics to prevent surgical site infection after breast cancer surgery. Cochrane Database Syst Rev. https://doi.org/10.1002/14651858. CD005360.pub4

263. Naqvi MA, Mehraj A, Ejaz R, Mian A (2013) Role of prophylactic antibiotics in low risk elective laparoscopic cholecystectomy: is there a need? J Ayub Med Coll Abbottabad 25(1-2):172-174

264. Wang J, Ji G, Yang Z et al (2013) Prospective randomized, double-blind, placebo controlled trial to evaluate infection prevention in adult patients after tension-free inguinal hernia repair. Int J Clin Pharmacol Ther 51(12):924-931 
265. Fahim $F$ (2012) Chemoprophylaxis in surgical site infection: is it really necessary. J Postgrad Med Inst 26(4):408-411

266. Gregoriou $O$, Bakas $P$, Grigoriadis $C$, Creatsa M, Sofoudis C, Creatsas G (2012) Antibiotic prophylaxis in diagnostic hysteroscopy: is it necessary or not? Eur J Obstet Gynecol Reprod Biol 163(2):190-192

267. Karanlik H, Kurul S, Saip P et al (2011) The role of antibiotic prophylaxis in totally implantable venous access device placement: results of a single-center prospective randomized trial. Am J Surg 202(1):10-15

268. Sanabria A, Dominguez LC, Valdivieso E, Gomez $\mathrm{G}$ (2010) Antibiotic prophylaxis for patients undergoing elective laparoscopic cholecystectomy. Cochrane Database Syst Rev. https:// doi.org/10.1002/14651858.CD005265.pub2

269. Ergul Z, Akinci M, Ugurlu C, Kulacoglu H, Yilmaz KB (2012) Prophylactic antibiotic use in elective inguinal hernioplasty in a trauma center. Hernia 16(2):145-151

270. Yang Z (2001) Short-term versus long-term antimicrobial prophylaxis in abdominal surgery: a multicenter open randomized comparative trial. Zhonghua Wai Ke Za Zhi 39(10):770-772

271. Lewis RT, Weigand FM, Mamazza J, Lloyd-Smith W, Tataryn D (1995) Should antibiotic prophylaxis be used routinely in clean surgical procedures: a tentative yes. Surgery 118(4):742-746

272. Wacha H, Hoyme U, Isenmann R et al (2010) Perioperative Antibiotika-Prophylaxe Empfehlungen einer Expertenkommission der Paul-EhrlichGesellschaft für Chemotherapie e. V. Chemother J 19(3):70-84

273. Forouzannia SK, Karimi-Bondarabadi AA, Bagherinasab M, Sarebanhassanabadi M (2014) Comparison of the effectiveness of continuous versus intermittent cefazolin for the prevention of infection after off-pump coronary artery bypass graft. JTehran Heart Cent 9(3):120-123

274. Ahn BK, Lee KH (2013) Single-dose antibiotic prophylaxis is effective enough in colorectal surgery. ANZ J Surg 83(9):641-645

275. Khalighi K, Aung TT, Elmi F (2014) The role of prophylaxis topical antibiotics in cardiac device implantation. Pacing Clin Electrophysiol 37(3):304-311

276. Haga $\mathrm{N}$, Ishida $\mathrm{H}$, Ishiguro $T$ et al (2012) $A$ prospective randomized study to assess the optimal duration of intravenous antimicrobial prophylaxis in elective gastric cancer surgery. Int Surg 97(2):169-176

277. Rajabi-Mashhadi MT, Mousavi SH, K-M MH, Ghayour-Mobarhan M, Sahebkar A (2012) Optimum duration of perioperative antibiotic therapy in patients with acute non-perforated appendicitis: a prospective randomized trial. Asian Biomed (Res Rev News) 6(6):891-894

278. Hirokawa F, Hayashi M, Miyamoto Y et al (2013) Evaluation of postoperative antibiotic prophylaxis after liver resection: a randomized controlled trial. Am J Surg 206(1):8-15

279. Lyimo FM, Massinde AN, Kidenya BR, Konje ET, Mshana SE (2013) Single dose of gentamicin in combination with metronidazole versus multiple doses for prevention of post-caesarean infection at Bugando Medical Centre in Mwanza, Tanzania: a randomized, equivalence, controlled trial. BMC Pregnancy Childbirth 13:123

280. Oxman DA, Issa NC, Marty FM et al (2013) Postoperative antibacterial prophylaxis for the prevention of infectious complications associated with tube thoracostomy in patients undergoing elective general thoracic surgery: a double-blind, placebo-controlled, randomized trial. JAMA Surg 148(5):440-446

281. Ali M, Nadeem M, Shah S, Khan M, Ahmad M, Ullah M (2012) Prolonged versus short course of antibiotic prophylaxis in clean general surgery. Med Sci (Peshawar) 20(3):128-132

282. Lin MH, Pan SC, Wang JL et al (2011) Prospective randomized study of efficacy of 1-day versus 3-day antibiotic prophylaxis for preventing surgical site infection after coronary artery bypass graft. J Formos Med Assoc 110(10):619-626

283. Tamayo E, Gualis J, Flórez S, Castrodeza J, Eiros Bouza JM, Álvarez FJ (2008) Comparative study of single-dose and 24-hour multiple-dose antibiotic prophylaxis for cardiac surgery. J Thorac Cardiovasc Surg 136(6):1522-1527

284. Fujita S, Saito N, Yamada T et al (2007) Randomized, multicenter trial of antibiotic prophylaxis in elective colorectal surgery: single dose vs 3 doses of a second-generation cephalosporin without metronidazole and oral antibiotics. Arch Surg 142(7):657-661

285. Gopinathan V, Sivanandan I (2012) Preventing surgical site infection (SSI) -are we getting it right with antibiotics? Anaesthesia 67(Suppl s2):47-48

286. Ryska O, Serclova Z, Konecna E et al (2012) Antibiotic prophylaxis administered without proper timing does not reduse surgical site infections after appendectomy. Poster session presented at the meeting of the Society of Coloproctology

287. Zanetti G, Flanagan HL Jr., Cohn LH, Giardina R, Platt R (2003) Improvement of intraoperative antibiotic prophylaxis in prolonged cardiac surgery by automated alerts in the operating room. Infect Control Hosp Epidemiol 24(1):13-16

288. Arbeitskreis Krankenhaus- und Praxishygiene der AWMF (2012) AWMF-Leitlinien-Register 029/022 - Leitlinien zur Hygiene in Klinik und Praxis: Perioperative Antibiotikaprophylaxe (URL: http://www.awmf.org/leitlinien/detail/ II/029-022.html)

289. Parvizi J, Saleh KJ, Ragland PS, Pour AE, Mont MA (2008) Efficacy of antibiotic-impregnated cement in total hip replacement. Acta Orthop Scand 79(3):335-341

290. Wang J, Zhu C, Cheng T et al (2013) A systematic review and meta-analysis of antibiotic-impregnated bone cement use in primary total hip or knee arthroplasty. PLoS ONE 8(12):e82745

291. Bistolfi A, Massazza G, Verné E et al (2011) Antibiotic-loaded cement in orthopedic surgery: a review. Isrn Orthop. https:// doi.org/10.5402/2011/290851

292. Sadahiro S, Suzuki T, Tanaka A et al (2014) Comparison between oral antibiotics and probiotics as bowel preparation for elective colon cancer surgery to prevent infection: prospective randomized trial. Surgery 155(3):493-503

293. Ishida H, Yokoyama M, Nakada H, Inokuma S, Hashimoto D (2001) Impact of oral antimicrobial prophylaxis on surgical site infection and methicillin-resistant staphylococcus aureus infection after elective colorectal surgery. Results of a prospective randomized trial. Surg Today 31(11):979-983

294. Morris MS, Graham LA, Chu DI, Cannon JA, Hawn MT (2015) Oral antibiotic bowel preparation significantly reduces surgical site infection rates and readmission rates in elective colorectal surgery. Ann Surg 261(6):1034-1040
295. Cannon JA, Altom LK, Deierhoi RJ et al (2012) Preoperative oral antibiotics reduce surgical site infection following elective colorectal resections. Dis Colon Rectum 55(11):1160-1166

296. Solla J, Rothenberger D (1990) Preoperative bowel preparation. Dis Colon Rectum 33(2):154159

297. Nichols RL, Smith JW, Garcia RY, Waterman RS, Holmes JWC (1997) Current practices of preoperative bowel preparation among North American Colorectal Surgeons. Clin Infect Dis 24(4):609-619

298. Horie T (2007) Randomized controlled trial on the necessity of chemical cleaning as preoperative preparation for Colorectal Cancer Surgery. Dokkyo J Med Sci 34(3):205-212

299. Pena-Soria M, Mayol J, Anula R, Arbeo-Escolar A, Fernandez-Represa J (2008) Single-blinded randomized trial of mechanical bowel preparation for colon surgery with primary intraperitoneal anastomosis. J Gastrointest Surg 12(12):21032109

300. Pena-Soria M, Mayol J, Anula-Fernandez R, Arbeo-Escolar A, Fernandez-Represa JA (2007) Mechanical bowel preparation for elective colorectal surgery with primary Intraperitoneal anastomosis by a single surgeon: interim analysis of a prospective single-blinded randomized trial. J Gastrointest Surg 11(5):562-567

301. Nelson RL, Glenny AM, Song F (2009) Antimicrobial prophylaxis for colorectal surgery. Cochrane Database Syst Rev. https:// doi.org/10.1002/14651858.CD001181.pub3

302. Bellows CF, Mills KT, Kelly TN, Gagliardi G (2011) Combination of oral non-absorbable and intravenous antibiotics versus intravenous antibiotics alone in the prevention of surgical site infections after colorectal surgery: a meta-analysis of randomized controlled trials. Tech Coloproctol 15(4):385-395

303. Barnes S, Spencer M, Graham D, Johnson HB (2014) Surgical wound irrigation: a call for evidence-based standardization of practice. Am J Infect Control 42(5):525-529

304. Högele AM, Neu J (2011) Wundverschluss nach Wundspülung mit Octenisept ${ }^{\circledR}$ ohne Abflussmöglichkeit. Unfallchirurg 114(1):70-72

305. Bauer B, Majic M, Rauthe S, Bröcker EB, Kerstan A (2012) Persistent swelling after flushing of an abscess with Octenisept ${ }^{\oplus}$. Unfallchirurg 115(12):1116-1119

306. Högele AM, Gill S, Körner M, Mayr D, Kernt B, Kanz KG (2011) Fat tissue necrosis after wound cleaning with Octenisept ${ }^{\oplus}$. Notf Rettungsmed 14(7):567-570

307. Wadhwa A, Kabon B, Fleischmann E, Kurz A, Sessler DI (2014) Supplemental postoperative oxygen does not reduce surgical site infection and major healing-related complications from bariatric surgery in morbidly obese patients: a randomized, blinded trial. Anesth Analg 119(2):357-365

308. Stall A, Paryavi E, Gupta R, Zadnik M, Hui E, O'Toole RV (2013) Perioperative supplemental oxygen to reduce surgical site infection after open fixation of high-risk fractures: a randomized controlled pilot trial. J Trauma Acute Care Surg 75(4):657-663

309. Duggal N, Poddatoori V, Noroozkhani S, SiddikAhmad Rl, Caughey AB (2013) Perioperative oxygen supplementation and surgical site infection after cesarean delivery: a randomized trial. Obstet Gynecol 122(1):79-84 
310. Thibon P, Borgey F, Boutreux S, Hanouz JL, Le Coutour X, Parienti JJ (2012) Effect of perioperative oxygen supplementation on 30-day surgical site infection rate in abdominal, gynecologic, and breast surgery: the ISO 2 randomized controlled trial. Anesthesiology 117(3):504-511

311. Bickel A, Gurevits M, Vamos R, Ivry S, Eitan A (2011) Perioperative hyperoxygenation and wound site infection following surgery for acute appendicitis: a randomized, prospective, controlled trial. Arch Surg 146(4):464-470

312. Meyhoff CS, Wetterslev J, Jorgensen LN et al (2009) Effect of high perioperative oxygen fraction on surgical site infection and pulmonary complications after abdominal surgery: the proxi randomized clinical trial. JAMA 302(14):15431550

313. Gardella C, Goltra LB, Laschansky E et al (2008) High-concentration supplemental perioperative oxygen to reduce the incidence of postcesarean surgical site infection: a randomized controlled trial. Obstet Gynecol 112(3):545-552

314. Belda F, Aguilera L, García de la Asunción J et al (2005) Supplemental perioperative oxygen and the risk of surgical wound infection: a randomized controlled trial. JAMA 294(16):2035-2042

315. Pryor KO, Fahey IT, Lien CA, Goldstein PA (2004) Surgical site infection and the routine use of perioperative hyperoxia in a general surgical population: a randomized controlled trial. JAMA 291(1):79-87

316. Qadan M, Akça O, Mahid SS, Hornung CA, Polk HC Jr (2009) Perioperative supplemental oxygen therapy and surgical site infection: a metaanalysis of randomized controlled trials. Arch Surg 144(4):359-366

317. Ford CD, VanMoorleghem G, Menlove RL (1993) Blood transfusions and postoperative wound infection. Surgery 113(6):603-607

318. Horvath KA, Acker MA, Chang $\mathrm{H}$ et al (2013) Blood transfusion and infection after cardiac surgery. Ann Thorac Surg 95(6):2194-2201

319. Wong PF, Kumar S, Bohra A, Whetter D, Leaper DJ (2007) Randomized clinical trial of perioperative systemic warming in major elective abdominal surgery. Br J Surg 94(4):421-426

320. Sessler DI (2001) Complications and treatment of mild hypothermia. Anesthesiology 95(2):531-543

321. Melling AC, Ali B, Scott EM, Leaper DJ (2001) Effects of preoperative warming on the incidence of wound infection after clean surgery: a randomised controlled trial. Lancet 358(9285):876-880

322. Flores-Maldonado A, Medina-Escobedo CE, RiosRodriguez HMG, Fernández-Dominguez R (2001) Mild perioperative hypothermia and the risk of wound infection. Arch Med Res 32(3):227-231

323. Verband der Elektrotechnik Elektronik Informationstechnik (VDE), Deutsche Gesellschaft für Biomedizinische Technik (DGMBT), Brandt S, Mühlsteff J, Imhoff M (2013) Akzidentelle Hypothermie -Diagnose, Prävention und Therapie. (VDE-Positionspapier ) VDE: Frankfurt am Main

324. Lehtinen SJ, Onicescu G, Kuhn KM, Cole DJ, Esnaola NF (2010) Normothermia to prevent surgical site infections after gastrointestinal surgery: holy grail or false idol? Ann Surg 252(4):696-704

325. Weimann A (2016) Hygienische Aufgabenstellungen in medizinischen und sozialen Einrichtungen. In: Kramer A, Assadian O, Exner M, Hübner NO, Simon A (Hrsg) Krankenhaus- und Praxishygiene. Hygienemanagement und Infek- tionsprävention in medizinischen und sozialen Einrichtungen, 3. Aufl. Elsevier, München

326. Latham R, Lancaster AD, Covington JF, Pirolo JS, Thomas CS Jr. (2001) The association of diabete and glucose control with surgical-site infections among cardiothoracic surgery patients. Infect Control Hosp Epidemiol 22(10):607-612

327. Chuang SC, Lee KT, Chang WT et al (2004) Risk factors for wound infection after cholecystectomy. J Formos Med Assoc 103(8):607-612

328. Al-Niaimi AN, Ahmed M, Burish N et al (2015) Intensive postoperative glucose control reduces the surgical site infection rates in gynecologic oncology patients. Gynecol Oncol 136(1):71-76

329. Mejia J, Sadurní M, Vilà E, Zalbidea M, Cantillo $J$ Escolano F (2014) Diabetes mellitus as a risk factor for surgical site infection in colorectal surgery. Does preoperative and postoperative glycemic control matter? Eur J Anaesthesiol 31:205-206

330. Liu Z, Qin H, Yang Z et al (2011) Randomised clinical trial: the effects of perioperative probiotic treatment on barrier function and postoperative infectious complications in colorectal cancer surgery - a double-blind study. Aliment Pharmacol Ther 33(1):50-63

331. Linton $\mathrm{AH}$, Hinton $\mathrm{MH}$ (1988) Enterobacteriaceae associated with animals in health and disease. Soc Appl Bacteriol Symp Ser 17:71S-85S

332. Wells CL (1990) Relationship between intestinal microecology and the translocation of intestinal bacteria. Antonie Van Leeuwenhoek 58(2):87-93

333. Rayes N, Seehofer D, Hansen S et al (2002) Early enteral supply of lactobacillus and fiber versus selective bowel decontamination: a controlled trial in liver transplant recipients. Transplantation 74(1):123-127

334. Rayes N, Hansen S, Seehofer D et al (2002) Early enteral supply of fiber and Lactobacilli versus conventional nutrition: a controlled trial in patients with major abdominal surgery. Nutrition 18(7/8):609-615

335. Rayes N, Seehofer D, Muller AR, Hansen S, Bengmark S, Neuhaus P (2002) Influence of probiotics and fibre on the incidence of bacterial infections following major abdominal surgery - results of a prospective trial. Z Gastroenterol 40(10):869-876

336. Sugawara G, Nagino M, Nishio H et al (2006) Perioperative synbiotic treatment to prevent postoperative infectious complications in biliary cancer surgery: a randomized controlled trial. Ann Surg 244(5):706-714

337. Aisu N, Tanimura SHU, Yamashita Y et al (2015) Impact of perioperative probiotic treatment for surgical site infections in patients with colorectal cancer. Exp Ther Med 10(3):966-972

338. Falcao de Arruda IS, de Aguilar-Nascimento JE (2004) Benefits of early enteral nutrition with glutamine and probiotics in brain injury patients. Clin Sci 106(3):287-292

339. European Centre for Disease Prevention and Control (ECDC) (2016) Invasive cardiovascular infection by Mycobacterium chimaera potentially associated with heater-cooler units used during cardiac surgery. (Rapid Risk Assessment). ECDC, Stockholm (URL: https://ecdc.europa.eu/sites/ portal/files/media/en/publications/Publications/ RRA-mycobacterium-chimaera-November-2016. pdf)

340. Robert Koch-Institut (RKI) (2016) Informationen zu einem internationalen Ausbruchsgeschehen mit nicht-tuberkulösen Mykobakterien im Zusammenhang mit Temperaturregulierungsgeräten bei Herzoperationen. RKI, Berlin (URL:https://www.rki.de/DE/Content/Infekt/ Krankenhaushygiene/Aufb_MedProd/Mycobacterium_chimaera.html). Zugegriffen: 6 . Sept. 2017

341. Sommerstein R, Schreiber PW, Diekema DJ et al (2017) Mycobacterium chimaera outbreak associated with heater-cooler devices: piecing the puzzle together. Infect Control Hosp Epidemiol 38(1):103-108

342. Erichsen Andersson A, Petzold M, Bergh I, Karlsson J, Eriksson BI, Nilsson K (2014) Comparison between mixed and laminar airflow systems in operating rooms and the influence of human factors: experiences from a Swedish orthopedic center. Am J Infect Control 42(6):665-669

343. Pasquarella C, Sansebastiano GE, Ferretti $S$ et al (2007) A mobile laminar airflow unit to reduce air bacterial contamination at surgical area in a conventionally ventilated operating theatre. J Hosp Infect 66(4):313-319

344. Friberg $S$, Ardnor B, Lundholm R, Friberg B (2003) The addition of a mobile ultra-clean exponential laminar airflow screen to conventional operating room ventilation reduces bacterial contamination to operating box levels. J Hosp Infect 55(2):92-97

345. Ahl T, Dalen N, Jörbeck H, Hobom J (1995) Air contamination during hip and knee arthroplasties: horizontal laminar flow randomized vs. conventional ventilation. Acta Orthop Scand 66(1):17-20

346. Taylor GJS, Bannister GC, Leeming JP (1995) Wound disinfection with ultraviolet radiation. J Hosp Infect 30(2):85-93

347. Lidwell OM, Lowbury EJ, Whyte W, Blowers $\mathrm{R}$ Stanley SJ, Lowe D (1983) Airborne contamination of wounds in joint replacement operations: the relationship to sepsis rates. J Hosp Infect 4(2):111-131

348. Whyte W, Hodgson R, Tinkler J (1982) The importance of airborne bacterial contamination of wounds. J Hosp Infect 3(2):123-135

349. Nelson JP (1976) Five years experience with operating room clean rooms and personnel-isolator systems. Med Instrum 10(6):277-281

350. Ritter MA, Stringer EA (1980) Laminar air-flow versus conventional air operating systems: a seven-year patient follow-up. Clin Orthop Relat Res 150:177-180

351. Diab-Elschahawi M, Berger J, Blacky A et al (2011) Impact of different-sized laminar air flow versus no laminar air flow on bacterial counts in the operating room during orthopedic surgery. Am J Infect Control 39(7):e25-e29

352. Aboelela SW, Stone PW, Larson EL (2007) Effectiveness of bundled behavioural interventions to control healthcare-associated infections: a systematic review of the literature. J Hosp Infect 66(2):101-108

353. Hirsch $T$, Hubert $H$, Fischer $S$ et al (2012) Bacterial burden in the operating room: impact of airflow systems. Am J Infect Control 40(7):e228-e232

354. Smith EB, Raphael IJ, Maltenfort MG, Honsawek S, Dolan K, Younkins EA (2013) The effect of laminar air flow and door openings on operating room contamination. J Arthroplasty 28(9):14821485

355. Seropian R, Reynolds BM (1969) The importance of airborne contamination as a factor in postoperative wound infection. Arch Surg 98(5):654-658 
356. van Griethuysen AJ, Spies-van Rooijen NH, Hoogenboom-Verdegaal AM (1996) Surveillance of wound infections and a new theatre: unexpected lack of improvement. J Hosp Infect 34(2):99-106

357. Hansen D, Krabs C, Benner D, Brauksiepe A, Popp W (2005) Laminar air flow provides high air quality in the operating field even during real operating conditions, but personal protection seems to be necessary in operations with tissue combustion. Int J Hyg Environ Health 208(6):455-460

358. Talon D, Schoenleber T, Bertrand X, Vichard $P$ (2006) Performances of different types of airflow system in operating theatre. Ann Chir 131(5):316-321

359. Hell KRH, Allgoewer M (1976) Comparative bacteriologic study of sterile chamber and conventionally ventilated operating theater with stimulated operations. Helv Chir Acta 43(12):157-160

360. Iudicello S, Fadda A (2013) A road map to a comprehensive regulation on ventilation technology for operating rooms. Infect Control Hosp Epidemiol 34(08):858-860

361. Lidwell OM, Elson RA, Lowbury EJL et al (1987) Ultraclean air and antibiotics for prevention of postoperative infection: a multicenter study of 8,052 joint replacement operations. Acta Orthop Scand 58(1):4-13

362. Nelson JP (1977) The operating room environment and its influence on deep wound infection. In: Murray WR (Hrsg) The hip. Proceedings of the Fifth Open Scientific Meeting of the Hip Society. CV Mosby, St. Louis, S 129-146

363. Lidwell O, Lowbury E, Whyte W, Blowers R, Stanley S, Lowe D (1982) Effect of ultraclean air in operating rooms on deep sepsis in the joint after total hip or knee replacement: a randomised study. BMJ 285(6334):10-14

364. Miner AL, Losina E, Katz JN, Fossel AH, Platt $R$ (2007) Deep infection after total knee replacement: impact of laminar airflow systems and body exhaust suits in the modern operating room. Infect Control Hosp Epidemiol 28(2):222-226

365. Breier A-C, Brandt C, Sohr D, Geffers C, Gastmeier $P$ (2011) Laminar airflow ceiling size: no impact on infection rates following hip and knee prosthesis. Infect Control Hosp Epidemiol 32(11):1097-1102

366. Hooper GJ, Rothwell AG, Frampton C, Wyatt MC (2011) Does the use of laminar flow and space suits reduce early deep infection after total hip and knee replacement? The ten-year results of the New Zealand Joint Registry. J Bone Joint Surg Br 93(1):85-90

367. Zheng H, Barnett AG, Merollini Ket al (2014) Control strategies to prevent total hip replacement-related infections: a systematic review and mixed treatment comparison. BMJ Open 4(3):e3978

368. Bischoff $P$, Kubilay NZ, Allegranzi B, Egger M, Gastmeier P (2017) Effect of laminar airflow ventilation on surgical site infections: a systematic review and meta-analysis. Lancet Infect Dis 17(5):553-561

369. Winkler T, Trampuz A, Hardt S, Janz V, Kleber C, Perka C (2014) Periprothetische Infektion nach Hüftendoprothetik. Orthopäde 43(1):70-78

370. Uckay I, Lubbeke A, Emonet S et al (2009) Low incidence of haematogenous seeding to total hip and knee prostheses in patients with remote infections. J Infect 59(5):337-345

371. Weist K, Krieger J, Rüden H (1988) Vergleichende Untersuchungen bei aseptischen und septischen Operationen unter besonderer Berücksichtigung von S. Aureus. Hyg Med 13:369-374

372. Harnoss J-C, Assadian O, Diener MK et al (2017) Mikrobielle Belastung in septischen und aseptischen Operationsräumen. Dtsch Arztebl Int 114(27-28):465-472

373. Kuntz L, Mennicken R, Scholtes S (2014) Stress on the ward: evidence of safety tipping points in hospitals. Manage Sci 61(4):754-771

374. Sprivulis PC, Da Silva JA, Jacobs IG, Frazer AR, Jelinek GA (2006) The association between hospital overcrowding and mortality among patients admitted via Western Australian emergency departments. Med J Aust 184(5):208-212

375. Deutsche Gesetzliche Unfallversicherung (DGUV), Spitzenverband der landwirtschaftlichen Sozialversicherung (LSV-SpV) (2013) Anforderungen der gesetzlichen Unfallversicherungsträger nach § 34 SGB VII an Krankenhäuser zur Beteiligung am Schwerstverletzungsartenverfahren (SAV) in der Fassung vom 1. Januar 2013 (URL: http://www.dguv.de/medien/landesverbaende/de/med_reha/documents/sav1.pdf)

376. Cabrales RA, Cobo RB, Patiño YDB, Quintero MFO, Martínez JW, Upegui MLC (2014) Effectiveness of silver dressings in preventing surgical site infection in contaminated wounds. latreia 27(3):247-254

377. Siah CJ, Yatim J (2011) Efficacy of a total occlusive ionic silver-containing dressing combination in decreasing risk of surgical site infection: an RCT. J Wound Care 20(12):561-568

378. Borkar NB, Khubalkar MV (2011) Are postoperative dressings necessary? J Wound Care 20(6):301

379. Simek M, Grulichova J, Langova K, Lonsky V, Jecminkova L (2008) Silver-containing hydrofiber dressing versus topical antiseptics in the treatment of surgical site infection in cardiac surgery. Prospective randomized study. Poster session presented at the meeting of the European Wound Mangement Asseciation (EWMA).

380. Takahashi S, Takeyama K, Hashimoto K et al (2006) Disinfection by antiseptics in management of postoperative surgical wounds in urologic operations. Hinyokika Kiyo 52(2):89-94

381. Veiga-Filho J, Veiga DF, Sabino-Neto $M$ et al (2012) Dressing wear time after reduction mammaplasty: a randomized controlled trial. Plast Reconstr Surg 129(1):1e-7e

382. Zhou HB, Wu Y, Wang LQ, Zou SL, Qiao YZ, Wang LX (2012) Feasibility and safety of early removal of incisional dressings following thoracic surgery. Med Princ Pract 21(4):379-382

383. Toon CD, Ramamoorthy R, Davidson BR, Gurusamy KS (2013) Early versus delayed dressing removal after primary closure of clean and clean-contaminated surgical wounds. Cochrane Database Syst Rev. https:// doi.org/10.1002/14651858.CD010259.pub3

384. Dumville JC, Gray TA, Walter CJ, Sharp CA, Page $T$ (2014) Dressings for the prevention of surgical site infection. Cochrane Database Syst Rev. https://doi.org/10.1002/14651858.CD003091. pub3

385. Towfigh S, Clarke T, Yacoub W et al (2011) Significant reduction of wound infections with daily probing of contaminated wounds: a prospective randomized clinical trial. Arch Surg 146(4):448452
386. Teshima H, Kawano H, Kashikie H et al (2009) A new hydrocolloid dressing prevents surgical site infection of median sternotomy wounds. Surg Today 39(10):848-854

387. Maier S, Heidecke C, Kramer A (2014) Prävention von Surgical Site Infections (SSI). ZentralbI Chir 139(2):139-144

388. Kramer A, Schilling M, Heidecke CD (2010) Infektionspräventions-Check-in und Infektionspräventions-Check-out zur Prävention nosokomialer Infektionen. Zentralbl Chir 135(01):44-48

389. Wartman SA, Morlock LL, Malitz FE, Palm EA (1983) Patient understanding and satisfaction as predictors of compliance. Med Care 21(9):886891

390. Brandt C, Sohr D, Behnke M, Daschner F, Rüden $\mathrm{H}$, Gastmeier $\mathrm{P}$ (2006) Reduction of surgical site infection rates with the help of benchmark data. Infect Control Hosp Epidemiol 27:1347-1351

391. Geubbels ELPE, Nagelkerke NJD, Mintjes-De Groot AJ, Vandenbroucke-Grauls CMJE, Grobbee DE, De Boer AS (2006) Reduced risk of surgical site infections through surveillance in a network. Int J Qual Health Care 18(2):127-133

392. Gastmeier P, Sohr D, Brandt C, Eckmanns T, Behnke M, Rüden H (2005) Reduction of orthopaedic wound infections in 21 hospitals. Arch Orthop Trauma Surg 125(8):526-530

393. Bärwolff S, Sohr D, Geffers C et al (2006) Reduction of surgical site infections after Caesarean delivery using surveillance. J Hosp Infect 64(2):156-161

394. Mabit C, Marcheix PS, Mounier M et al (2012) Impact of a surgical site infection (SSI) surveillance program in orthopedics and traumatology. Orthop Traumatol Surg Res 98(6):690-695

395. Worth LJ, Bull AL, Spelman T, Brett J, Richards MJ (2015) Diminishing surgical site infections in Australia: time trends in infection rates, pathogens and antimicrobial resistance using a comprehensive Victorian surveillance program, 2002-2013. Infect Control Hosp Epidemiol 36(4):409-416

396. Nationales Referenzzentrum für Surveillance von nosokomialen Infektionen (NRZ) (Hrsg) (2017) Definitionen nosokomialer Infektionen für die Surveillance im Krankenhaus-InfektionsSurveillance-System (KISS-Definitionen). Robert Koch-Institut, Berlin

397. Le T, Dibley MJ, Nho VV, Archibald L, Jarvis WR, Sohn AH (2007) Reduction in surgical site infections in neurosurgical patients associated with a bedside hand hygiene program in Vietnam. Infect Control Hosp Epidemiol 28(5):583-588

398. Weinberg M, Fuentes J, Ruiz Al et al (2001) Reducing infections among women undergoing cesarean section in colombia by means of continuous quality improvement methods. Arch Intern Med 161(19):2357-2365

399. Pirotte BJ, Lubansu A, Bruneau M, Loqa C, Van Cutsem N, Brotchi J (2007) Sterile surgical technique for shunt placement reduces the shunt infection rate in children: preliminary analysis of a prospective protocol in 115 consecutive procedures. Childs Nerv Syst 23(11):1251-1261

400. Levent T, Vandevelde D, Delobelle JM et al (2010) Infection risk prevention following total knee arthroplasty. Orthop Traumatol Surg Res 96(1):49-56

401. Carboneau C, Benge $E$, Jaco MT, Robinson M (2010) A lean Six Sigma team increases hand hygiene compliance and reduces hospital-ac- 
quired MRSA infections by 51\%. J Healthc Qual 32(4):61-70

402. Corcoran S, Jackson V, Coulter-Smith S, Loughrey J, McKenna P, Cafferkey M (2013) Surgical site infection after cesarean section: implementing 3 changes to improve the quality of patient care. Am J Infect Control 41(12):1258-1263

403. Lavu H, Klinge MJ, Nowcid LJ et al (2012) Perioperative surgical care bundle reduces pancreaticoduodenectomy wound infections. J Surg Res 174(2):215-221

404. Trussell J, Gerkin R, Coates B et al (2008) Impact of a patient care pathway protocol on surgical site infection rates in cardiothoracic surgery patients. Am J Surg 196(6):883-889

405. Tanner J, Padley W, Assadian O, Leaper D, Kiernan M, Edmiston C (2015) Do surgical care bundles reduce the risk of surgical site infections in patients undergoing colorectal surgery? A systematic review and cohort meta-analysis of 8,515 patients. Surgery 158(1):66-77

406. Leaper DJ, Tanner J, Kiernan M, Assadian O, Edmiston CE (2014) Surgical site infection: poor compliance with guidelines and care bundles. Int Wound J 12(3):357-362

407. von Hagen C, Hansis M (1994) Verhaltensprobleme in der Krankenhaushygiene. Traumatologie aktuell, Bd. 15. Thieme, Stuttgart 